\title{
Vibrations of Plates with Complex Shape: Experimental Modal Analysis, Finite Element Method, and R-Functions Method
}

\author{
Antonio Zippo $\mathbb{D}^{1,2}$ Giovanni Iarriccio $(\mathbb{D})^{1,2}$ Francesco Pellicano ${ }^{1 D},{ }^{1,2}$ \\ and Tetyana Shmatko $\mathbb{1 0}^{3}$ \\ ${ }^{1}$ Department of Engineering "Enzo Ferrari", University of Modena and Reggio Emilia, Via P.Vivarelli 10, Modena 41124, Italy \\ ${ }^{2}$ Centre InterMech MoRe, University of Modena and Reggio Emilia, V. P. Vivarelli, 2, Modena 41124, Italy \\ ${ }^{3}$ Department of Higher Mathematics, National Technical University "KhPI", 2 Kyrpychova Str., Kharkov 61002, Ukraine
}

Correspondence should be addressed to Antonio Zippo; antonio.zippo@unimore.it

Received 14 August 2020; Revised 5 October 2020; Accepted 9 October 2020; Published 3 December 2020

Academic Editor: Jorge P. Arenas

Copyright ( $\odot 2020$ Antonio Zippo et al. This is an open access article distributed under the Creative Commons Attribution License, which permits unrestricted use, distribution, and reproduction in any medium, provided the original work is properly cited.

In this paper, the dynamic behavior of 3D-printed plates with different shapes and boundary conditions is investigated. The natural frequencies and mode shapes were determined using three different methods: the experimental analysis, the finite element method, using Nastran, and the $R$-functions method. The experimental and theoretical results are compared. The specimens tested included four cases. The test procedure is deeply described, and the material properties of the plates are given. The fixed-fixed configuration shows a better agreement both in the rectangular plate and in the plate with rectangular cuts, and the $R$-functions method gives better convergence with respect to the experimental and finite element analysis. The simply supported arrangement indicates some uncertainty in the boundary realization of the specimen.

\section{Introduction}

Today, composite and innovative materials are distributed very intensively through many industries, using even more polymeric and plastic materials that are becoming increasingly popular and are gaining more and more technical concern. They find applications in aerospace, automobile, medicine, sport, optoelectronics, and so on. Often, designing elements are plates and shallow shells. One of the main problems arising at the investigation of the structural elements is their dynamic behavior. Therefore, application of a new modern technology or practical and theoretical investigation of linear and nonlinear vibrations of composite plates and shallow shells with a complex form, various boundary conditions, and different properties of materials is a very actual problem. To model properly, the structural response of a system is needed to take into account several aspects of the environmental condition that can drastically affect the results. Theoretical and experimental aspects of nonlinear vibration and stability of shells and plates are explained in [1], where the author investigates, in a comprehensive and detailed approach, several traits of shells and plates from the design of traditional and advanced materials to fluid-structure interaction problems of shells.

In [2], the effect of the temperature has been studied on a thin circular cylindrical shell made of polyethylene terephthalate (PET) showing that temperature variations highlight the complex dynamics of the shell, as in [3], where the thermal gradient was applied. In [4], the role of the boundary conditions is highlighted by the authors that provided in a nonideal realization of the fixed-fixed joint, a possible reason for the difference between the experimental data and the modelling. Moreover, the outcome of the different boundary conditions has a lead role in annular sector plates as shown by Shi et al. [5], and in a recent work, Joubaneh et al. [6] studied the effect of various boundary conditions both analytically and experimentally.

In recent years, the use of innovative methods and technologies such as additive manufacturing and $3 \mathrm{D}$ printers is becoming increasingly popular both in the design phase and in the production phase. The use of these technologies 
allows on the one side the possibility to create prototypes or components faster and on the other to give the designer greater freedom in the use of shapes and profiles that cannot be achieved with traditional production methods. This freedom, however, translates into more complex structures with boundary conditions that are often difficult to define in the creation of models that can correctly describe their dynamic behavior. For this reason, it is necessary to have available, reliable, and versatile methods that allow to simulate the behavior of composite structures with complex shapes and boundary conditions.

The study of structural dynamics is essential to understand and evaluate the performances of any engineering product. The experimental modal analysis of the data obtained from the structural tests provides us with a definitive description of the response of a structure, which can be assessed based on the project specifications. Moreover, it is not always possible to perform experimental analysis during the design process due to budget limitations or uncertainness of technical specification; certain cases having available methods, experimentally validated, that allow to forecast the behavior of the structures under investigation and predict how the structure will behave under different operating conditions could speed up the design and development process.

One of the effective methods for realization of this problem is the $R$-functions theory. It is used as a numerical and analytical method for calculation of mode shapes and natural frequencies of the plates and shallow shells of a complex form with various boundary conditions. The main feature of the $R$-functions theory is that it can present the solution in an analytical form for developing nonlinear models, what differs it essentially from other methods [7-9]. This theory has a well-known abbreviation RFM ( $R$-functions method). Earlier, this method was applied in the papers [10-13]. Now, RFM is useful for verification of experimental data obtained by $3 \mathrm{D}$ printer application.

\subsection{Application of the R-Functions Theory to Solution of} Boundary Value Problems. The $R$-functions theory combined with the Ritz method (RFM) is an effective approach for the investigation of vibration characteristics of elastic structures having a complex geometry. The goal of this paper is to prove the efficiency and accuracy of the $R$-functions method of the solution of the boundary value problem by comparing with experimental data and other numerical methods in a particular case with FEM.

Let us consider a composite plate. To construct the mathematical model of the plate under experimental investigation, we use a classical plate theory based on the hypothesis Kirchhoff-Love. In the framework of this theory, the motion equation is the following:

$$
M_{11, x x}+M_{12 x y}+M_{22, y y}=\rho h w_{, t t},
$$

where $\rho$ and $h$ are the density and thickness of the plate relatively.
$M_{11}, M_{22}$, and $M_{12}$ are the stress resultants:

$$
\vec{M}=\left(\begin{array}{l}
M_{11} \\
M_{22} \\
M_{12}
\end{array}\right)=\left(\begin{array}{lll}
D_{11} & D_{12} & D_{16} \\
D_{12} & D_{22} & D_{26} \\
D_{16} & D_{26} & D_{66}
\end{array}\right)\left(\begin{array}{c}
-w_{, x x} \\
-w_{, y y} \\
-2 w_{, x y}
\end{array}\right) .
$$

For isotropic plates, the elements of matrix (2) have the following form:

$$
\vec{M}=\left(\begin{array}{c}
M_{11} \\
M_{22} \\
M_{12}
\end{array}\right)=\frac{E h^{3}}{12\left(1-v^{2}\right)}\left(\begin{array}{ccc}
1 & v & 0 \\
v & 1 & 0 \\
0 & 0 & \frac{1-v}{2}
\end{array}\right)\left(\begin{array}{c}
-w_{, x x} \\
-w_{, y y} \\
-2 w_{, x y}
\end{array}\right) .
$$

Motion equation is supplemented by corresponding boundary conditions. For the thin plates, two boundary conditions are set. Type of the boundary condition is determined by the fixing way of a plate edge. The boundary conditions for the most frequent ways of fixing for the curvilinear contour of the plate are as follows:

(i) Clamped edge:

$$
\begin{aligned}
w & =0, \\
\frac{\partial w}{\partial n} & =0,
\end{aligned}
$$

where $n$ is an external normal to the boundary $\partial \Omega$ of the domain $\Omega$ of the plate.

(ii) Simply supported edge:

$$
\begin{aligned}
w & =0, \\
M_{n} & =0,
\end{aligned}
$$

where

$$
M_{n}=M_{1} \cos ^{2} \alpha+M_{2} \sin ^{2} \alpha+2 M_{12} \cos \alpha \sin \alpha,
$$

$\alpha=(n, O x)$ is an angle between normal $n$ and the $O x$ axis.

(iii) Free edge:

$$
\begin{aligned}
M_{n} & =0, \\
Q_{n}-\frac{\partial M_{n \tau}}{\partial S} & =0,
\end{aligned}
$$

where 


$$
\begin{array}{r}
M_{n \tau}=\left(M_{2}-M_{1}\right) \cos \alpha \sin \alpha+M_{12}\left(\cos ^{2} \alpha-\sin ^{2} \alpha\right), \\
Q_{n}=Q_{1} \cos \alpha+Q_{2} \sin \alpha .
\end{array}
$$

According to the Ritz method solution of the motion, equation (1) is reduced to find the minimum of the following functional equation:

$$
I=U-V
$$

that is, to the solution of the variational equation:

$$
\delta(U-V)=0
$$

where $U$ and $V$ are the potential and kinetic energy of a plate relatively. They have the following type for isotropic plates:

$$
\begin{aligned}
& U(w)=\frac{1}{2} \iint_{\Omega}\left((\Delta w)^{2}+2(1-v)\left(\left(w,_{x y}\right)^{2}-w_{x x} w,_{y y}\right)\right) d \Omega \\
& V(w)=\frac{\rho h \Omega_{L}^{2}}{2} \iint_{\Omega} w^{2} d \Omega
\end{aligned}
$$

where $\rho$ is a curvature radius of the edge curve and $v$ is Poisson's ratio.

By Ritz's approach, the function $w$ is presented in the following type:

$$
w=\sum_{k=1}^{N} c_{k} w_{k}
$$

where functions $w_{k}$ are the admissible functions satisfying given boundary conditions and $c_{k}, k=\overline{1, N}$, are unknown constants that can be found from the following condition:

$$
\frac{\partial}{\partial c_{k}}\left(U-\Omega_{L}^{2} V\right)=0 .
$$

For the case of plates and shallow shells of complex shape, the difficulties are usually connected with the construction of an admissible functions system. These functions should be linearly independent and differentiable, generate the complete system, and satisfy at least the geometrical boundary conditions. Applying the $R$-functions theory, we can construct the sequence of the admissible functions for an arbitrary shape and different boundary conditions. At first, the corresponding solution structure should be built. Solution structure is defined as [14] the following expression:

$$
W=B\left(\Phi_{1}, \Phi_{2}, \ldots, \Phi_{k}, \omega, \omega_{i}\right) .
$$

Here, $W(x, y)$ is a displacement; $B$ is an operator depending on the system and its boundary conditions; $\Phi_{k}, k=\overline{1, m}$, are the indefinite components that are expanded into truncated series along some full system of functions $\left\{\varphi_{i}(x, y)\right\}$. For a complete system of functions $\varphi_{i}(x, y)$, power polynomials, Chebyshev's polynomials, trigonometric polynomials, splines, and others can be used. Functions $\omega(x, y)=0$ and $\omega_{i}(x, y)=0$ describe an equation of the domain boundary and some parts of the domain boundary. These functions are constructed by the $R$-functions theory and presented in analytical form.

The function $\omega(x, y)$ satisfies the following conditions:

$$
\begin{gathered}
\omega(x, y)>0, \quad \forall(x, y) \in \Omega, \\
\omega(x, y)<0, \quad \forall(x, y) \notin \Omega, \\
\omega(x, y)=0, \quad \forall(x, y) \in \partial \Omega, \\
\frac{\partial \omega(x, y)}{\partial n}=-1, \quad \forall(x, y) \in \partial \Omega .
\end{gathered}
$$

Functions satisfying condition (16) are constructed using the main system of the $R$-functions $R_{0}$ :

$$
\begin{aligned}
f_{1} \wedge_{\alpha} f_{2} & \equiv \frac{1}{1+\alpha}\left(f_{1}+f_{2}-\sqrt{f_{1}^{2}+f_{2}^{2}-2 \alpha f_{1} f_{2}}\right), \\
f_{1} \vee_{\alpha} f_{2} & \equiv \frac{1}{1+\alpha}\left(f_{1}+f_{2}+\sqrt{f_{1}^{2}+f_{2}^{2}-2 \alpha f_{1} f_{2}}\right), \\
\bar{f} & =-f .
\end{aligned}
$$

In practice, usually, the value $-1<\alpha\left(x_{1}, x_{2}\right) \leq 1$ is assumed to be zero, and the main system $R_{0}$ takes the more simple form $(\alpha \equiv 0)$ :

$$
\begin{aligned}
& \bar{f} \equiv-f, \\
& f_{1} \wedge_{0} f_{2} \equiv f_{1}+f_{2}-\sqrt{f_{1}^{2}+f_{2}^{2}}, \\
& f_{1} \vee_{0} f_{2} \equiv f_{1}+f_{2}+\sqrt{f_{1}^{2}+f_{2}^{2}},
\end{aligned}
$$

where functions $f_{1}(x, y) \geq 0$ and $f_{2}(x, y) \geq 0$ define domains $\Omega_{1}$ and $\Omega_{2}$. Note that formulas (17) and (18) define a region $\Omega$ that is the intersection, union of the regions $\Omega_{1}$ and outside of the region $\Omega$.

Let us present solution structures for boundary conditions (4), (5), and (7) which satisfy all boundary conditions [15].

(i) Clamped edge:

$$
w=\omega^{2} \Phi_{1}
$$

(ii) Simply supported edge:

$$
w=w \Phi_{1}-\frac{1}{2} \omega^{2}\left(\Phi_{1}-\left(D_{2} \omega-\frac{v}{\rho_{c}}\right)+2 D_{1} \Phi_{1}\right)
$$

(iii) Free edge: 


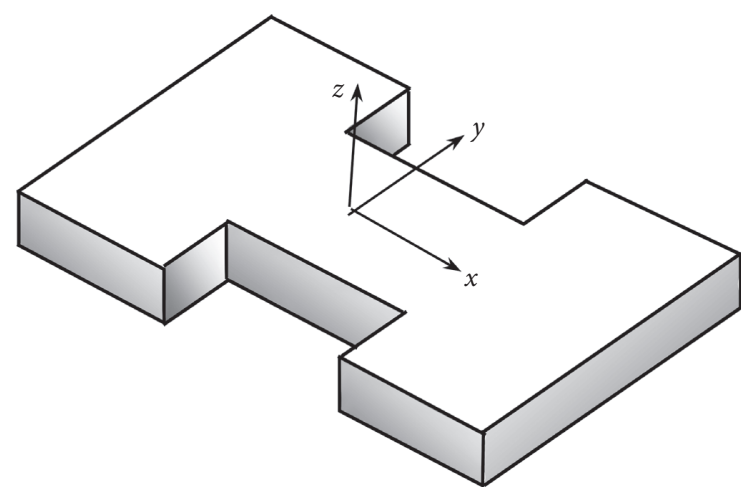

(a)

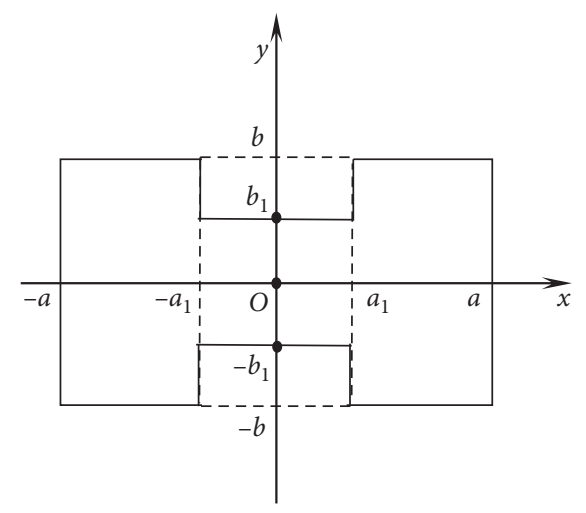

(b)

FIGURE 1: Planform of the composite plate with rectangular cuts.

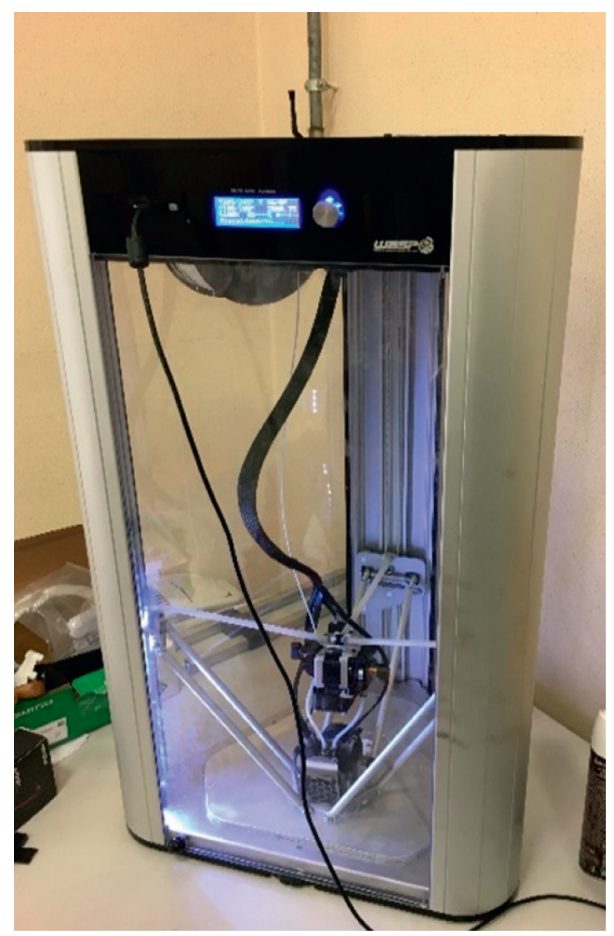

FIgUre 2: 3D printer, Delta Wasp 2040 Turbo 2.

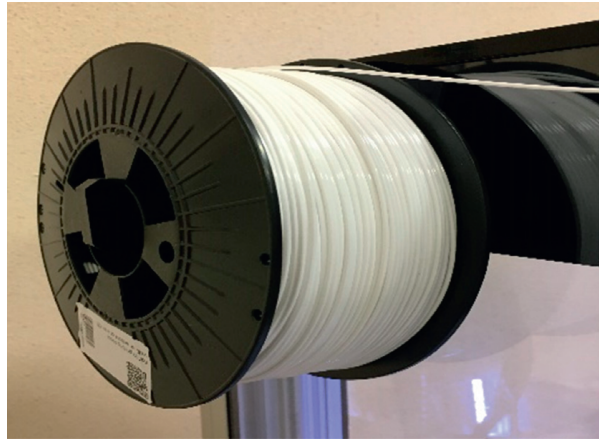

FIGURE 3: Detail of the printer: wire of PETG used for the 3D printing process. 


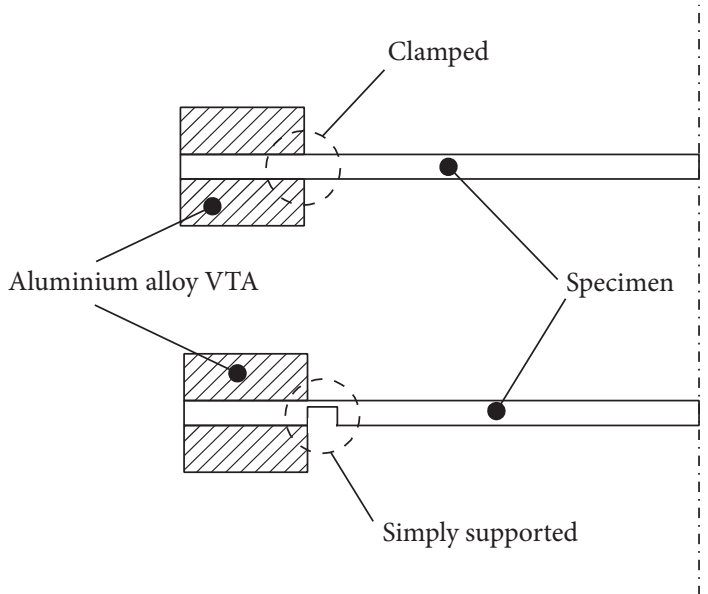

Figure 4: Drawing of clamped and simply supported BC.

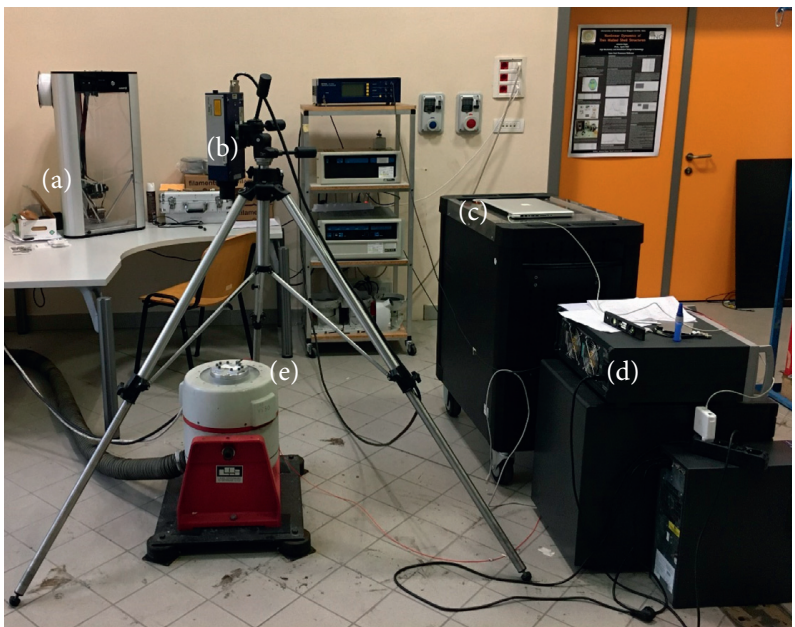

Figure 5: Picture of the experimental setup: (a) 3D printer, (b) laser vibrometer, (c) computer, (d) SCANDAS III, and (e) electrodynamic shaker.

TABle 1: Test cases.

\begin{tabular}{lcc}
\hline Case & Shape description & Boundary conditions \\
\hline 1 & Rectangular & 2 opposite sides clamped; 2 sides free \\
2 & Rectangular & All sides clamped \\
3 & Rectangular & All sides simply supported \\
4 & Rectangular with rectangular cut & 2 opposite sides clamped, other sides free \\
\hline
\end{tabular}

TABLE 2: Material properties used for FEM and RFM simulation.

\begin{tabular}{lc}
\hline Feature & G PET \\
\hline Mass density & $1.20 \mathrm{~g} / \mathrm{cm}^{\prime 3}$ \\
Yield strength & $50 \mathrm{MPa}$ \\
Ultimate tensile strength & $26 \mathrm{MPa}$ \\
Young's modulus & $1.6 \mathrm{GPa}$ \\
Poisson's ratio & $0.417 \mathrm{su}$ \\
Shear modulus & $0.564573 \mathrm{GPa}$ \\
\hline
\end{tabular}


TABLE 3: Geometrical properties and boundary conditions (Case 1).
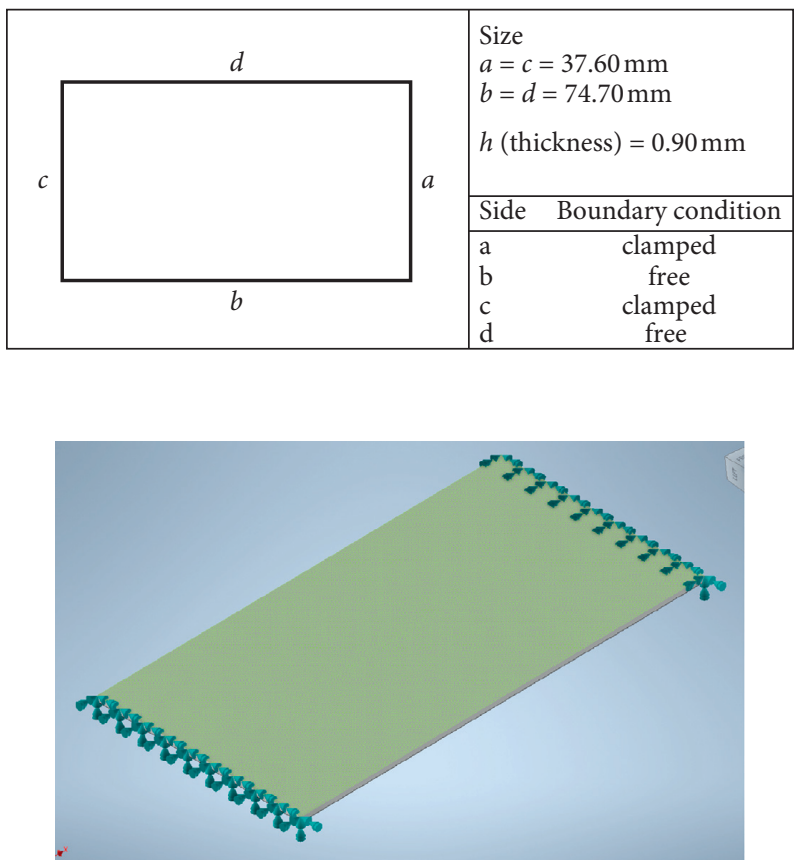

Figure 6: Numerical simulation: mesh and clamped edges.

$$
w=\Phi_{1}-\frac{1}{2} \omega^{2}\left(R+\frac{\omega}{3}\left(D_{3}+(2-\nu) D_{1} T_{2}-\frac{\nu-1}{\rho_{c}}\left(D_{2}-T_{2}\right)-3 D_{1} R\right) \Phi_{1}+R\left(3 D_{2} \omega-\frac{1}{\rho_{c}}\right)\right)
$$

Operators $D_{m}, \quad m=1,2,3$, in formulas (19)-(21) are defined as

$$
\begin{aligned}
D_{m} f & =(\nabla \omega, \nabla)^{m}=\left(\frac{\partial \omega}{\partial x} \frac{\partial}{\partial x}+\frac{\partial \omega}{\partial y} \frac{\partial}{\partial y}\right)^{m} f \\
T_{2} f & =\frac{\partial^{2} f}{\partial x^{2}}\left(\frac{\partial \omega}{\partial y}\right)^{2}-2 \frac{\partial^{2} f}{\partial x \partial y}\left(\frac{\partial \omega}{\partial x}\right)\left(\frac{\partial \omega}{\partial y}\right)+\frac{\partial^{2} f}{\partial y^{2}}\left(\frac{\partial \omega}{\partial x}\right)^{2} \\
R f & =\left(D_{2}+\nu T_{2}\right) f .
\end{aligned}
$$

$\Phi_{1}$ is an indefinite component.

Solution structures (19)-(21) contain function $\omega(x, y)=0$.

Now, let us take the following example. Considering a composite plate with the planform shown in Figure 1, where $a=37.5 \times 10^{-3} \mathrm{~m} ; \quad b=8.75 \times 10^{-3} \mathrm{~m} ; \quad a_{1}=12.5 \times 10^{-3} \mathrm{~m}$; $b_{1}=9.25 \times 10^{-3} \mathrm{~m}$.

Suppose that the plate is clamped along all the borders. In order to obtain the admissible functions, it is necessary to construct a solution structure (19), and the equation of the border $\omega(x, y)=0$. Using the $R$-operations $\wedge_{0}$ and $\vee_{0}$, the equation of the boundary is built in the following form:

$$
\omega=\left(f_{1} \wedge_{0} f_{2}\right) \wedge_{0}\left(f_{3} \vee_{0} f_{4}\right)
$$

where $f_{1}=\left(\left(a^{2}-x^{2}\right) / 2 a\right) \geq 0$ is the vertical band bounded by straight lines $x= \pm a, f_{2}=\left(\left(b^{2}-y^{2}\right) / 2 b\right) \geq 0$ is the horizontal band bounded by straight lines $y= \pm b, f_{3}=$ $\left(\left(x^{2}-a_{1}^{2}\right) / 2 a_{1}\right) \geq 0$ is an outside domain of the vertical band bounded by straight lines $x= \pm a_{1}$, $f_{4}=\left(\left(b_{1}^{2}-y^{2}\right) / 2 b_{1}\right) \geq 0$ is the horizontal band bounded by straight lines $y= \pm b_{1}$, and ${ }_{\omega}=0$ is the equation of the whole boundary domain.

Numerical implementation of the method of solving problems of linear vibrations of FG plates and shallow shells has been done in the system POLE-RL.

\section{Specimens Preparation}

As the goal of this work is the experimental validation of the $R$-functions method, the activity started with the definition of four geometries with different boundary conditions. Such structures were experimentally prototyped. Then, the finite element method and the $R$-functions method were used for modelling the system.

A $3 \mathrm{D}$ printer has been used to create the specimens, in such a way it was possible to obtain better accuracy and precise, clamped, and simply supported boundary conditions, as well as a complex shape.

The printer used, see Figure 2, is the Delta WASP 2040 Turbo2 that has been set with the following technical specification:

(i) Layer height: $0.15 \mathrm{~mm}$ 
TABLE 4: FEM simulation: mode shapes and natural frequencies (Case 1).

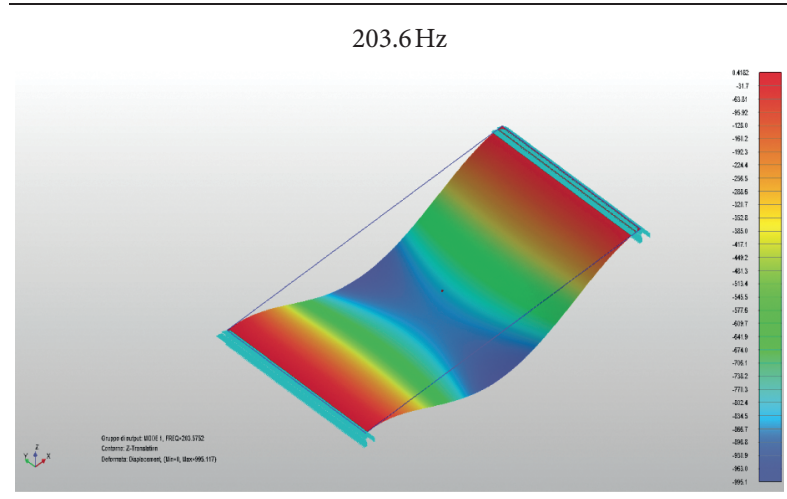

$560.4 \mathrm{~Hz}$

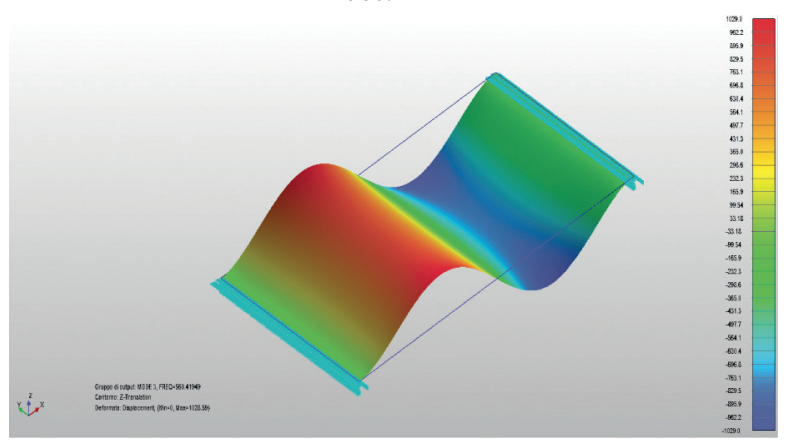

$998.6 \mathrm{~Hz}$

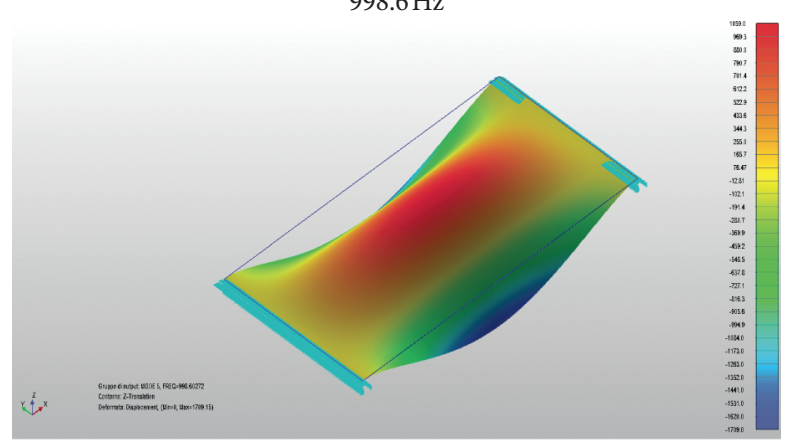

$1299.95 \mathrm{~Hz}$

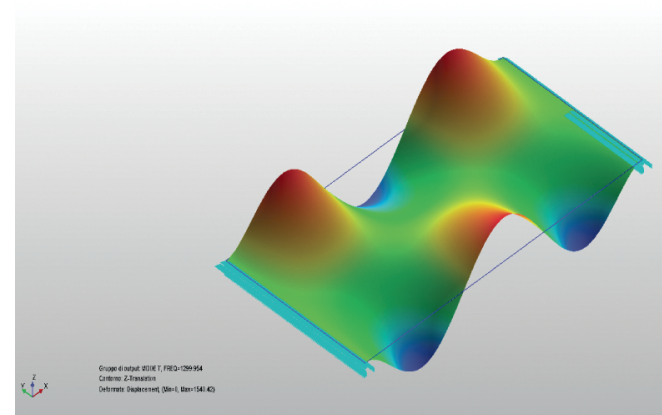

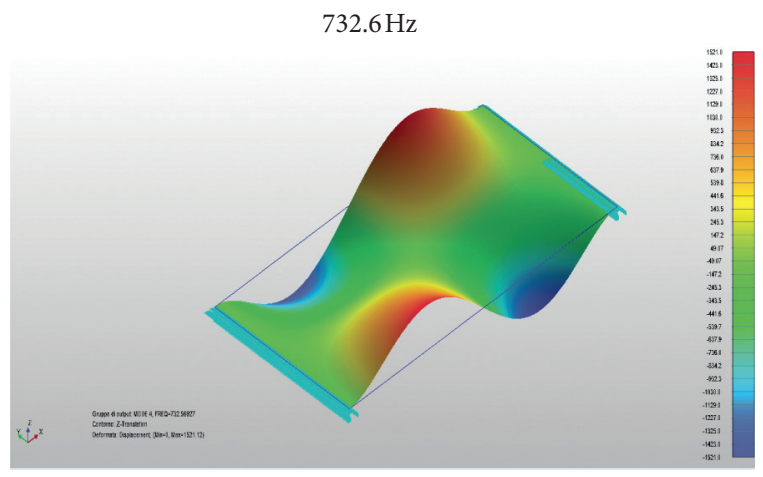

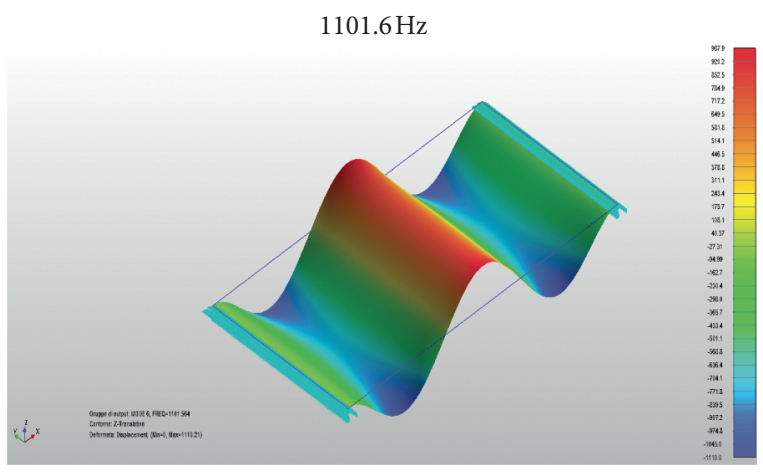

$1428.8 \mathrm{~Hz}$

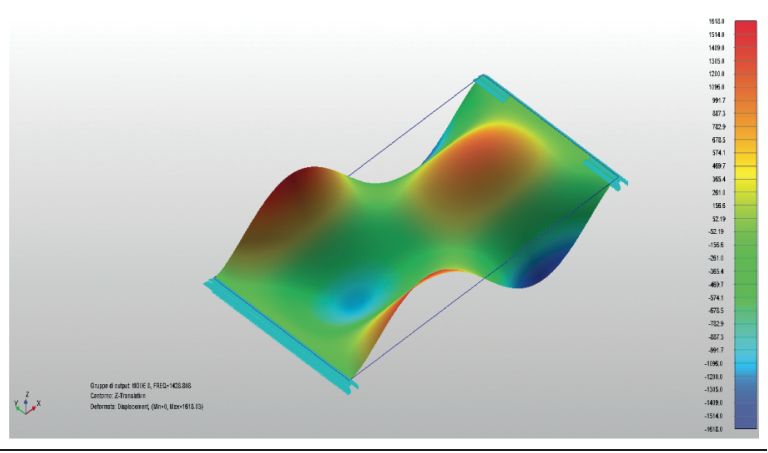




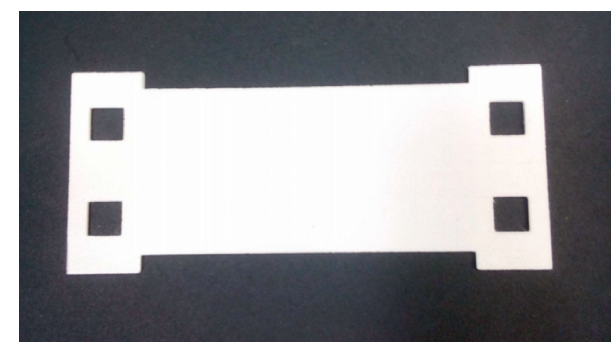

Figure 7: Specimen for experimental modal analysis (Case 1).

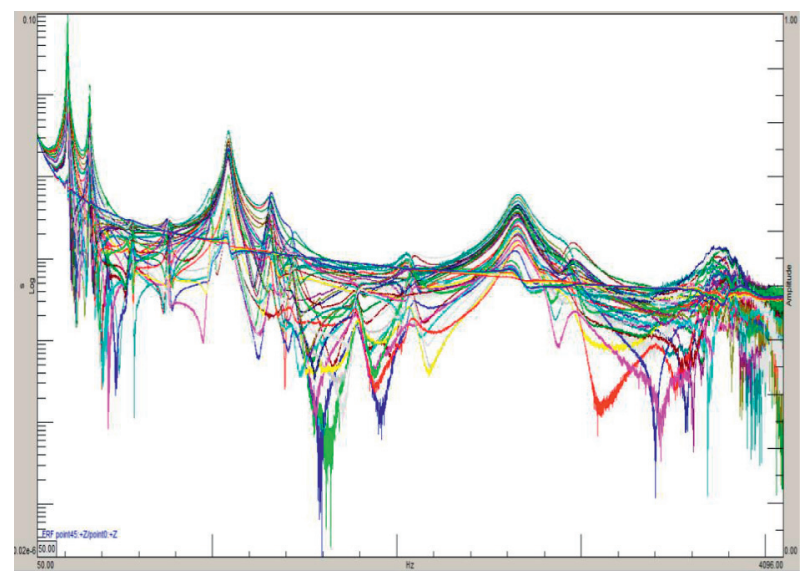

FIGURE 8: Experimental frequency response function base excitation vs velocity.

(ii) Print speed: $50 \mathrm{~mm} / \mathrm{s}$

(iii) Travel speed: $80 \mathrm{~mm} / \mathrm{s}$

(iv) Bed temperature: $60^{\circ} \mathrm{C}$

(v) Extruder temperature: $245^{\circ} \mathrm{C}$

(vi) Extruder/nozzle diameter: $0.4 \mathrm{~mm}$

All specimens have been made using the PETG filament of TREED, see Figure 3, with the following mechanical properties:

(i) Density: $1.20 \mathrm{~g} / \mathrm{cm}^{3}$

(ii) Young's modulus: $1.6 \mathrm{GPa}$

(iii) Water absorption: $0.13 \%$

As water absorption can affect the real weight of the specimen, in order to avoid unwanted mass variation, each specimen has been weighed before and after the testing process. Moreover, in order to avoid Young's modulus change, the same filament reel has been used for all the specimens.

The main issue in the prototype creation is the determination of the correct boundary condition. Figure 4 shows the drawing section of half of the samples, note that the dash-dot line is a symmetry axis, to highlight the realization of the fixed joint by locking the specimen between the VTA (vibration table adapter) made with two aluminum frames, suitably shaped, while the simply supported joint has been made by printing a thinner outline to allow rotations and lock displacements; indeed, super flexible joints behave similarly to hinges.

\section{Experimental Set-Up}

The equipment used for this experiment shown in Figure 5 consists of an electrodynamic shaker LDS V530 (Figure 5(e)) controlled with the SCADAS III data acquisition system (Figure 5(d)) and Siemens LMS Test Lab software: the bare table vibration is monitored with a Dytran monoaxial accelerometer model 3097a2, and the response is measured by a laser vibrometer OFV -505 by POLYTEC (Figure 5(b)). The shaker and cooling fan are powered by a power amplifier.

Specimens have been designed with a 3D cad and realized with a $3 \mathrm{D}$ printer using a slicing software; for each plate, an ad hoc aluminum VTA has been made to rigidly connect the specimen to the shaker. The printing process was repeated iteratively, modifying the printing parameters (extruder speed and temperature) in order to obtain homogeneous and uniform specimens. The dimensions of the specimens were carefully measured and used for the FEM and RFM simulations. The specimens were experimentally tested, and modal analysis was performed using about 45 measuring points for each plate. Experimental modal analysis by base excitation has been chosen due to the small size, the high damping, and the low stiffness of the samples: the measurement location has been accurately set; the base acceleration was carried out using sine sweep, allowing uniform energy distribution in the frequency range of interest; contactless sensors were used to avoid excessive perturbation of the system.

\section{Results and Discussion}

Four test cases are considered; for each one, the general properties and operating conditions were defined, the numerical modal analysis is reported, and afterward the experimental modal analysis is presented. The four cases differ in geometry and boundary conditions. Table 1 reports the definition of each test case and the relative boundary conditions, while Table 2 reports the reference material properties that have been used to investigate the cases with finite element simulation using Nastran and RFM simulations. Material properties could be subjected to small variations due to the $3 \mathrm{D}$ printing pattern and process such as water absorption or extruding temperature.

Case 1. Rectangular plate with 2 clamped edges.

In Table 3, the measured geometrical properties and the boundary conditions of the plate for the first case are listed.

4.1. FEM Simulation. For the finite element simulation, the Nastran solver has been used; in Figure 6, the mesh and the opposite clamped edges are shown; results are given in Table 4.

4.2. Experimental Modal Analysis. In Figure 7, the specimen realized with the $3 \mathrm{D}$ printer for the experimental modal analysis is shown, while in Figure 8, the experimental FRF (frequency response function) between the base acceleration of the excitation and the measured velocity response of each point is presented. In Table 5, experimental results are given. 
TABLE 5: Experimental modal analysis: mode shapes and natural frequencies (Case 1).

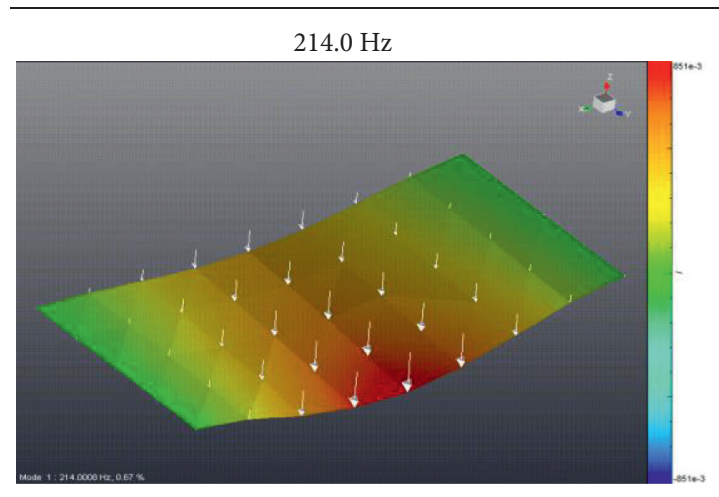

$566,7 \mathrm{~Hz}$

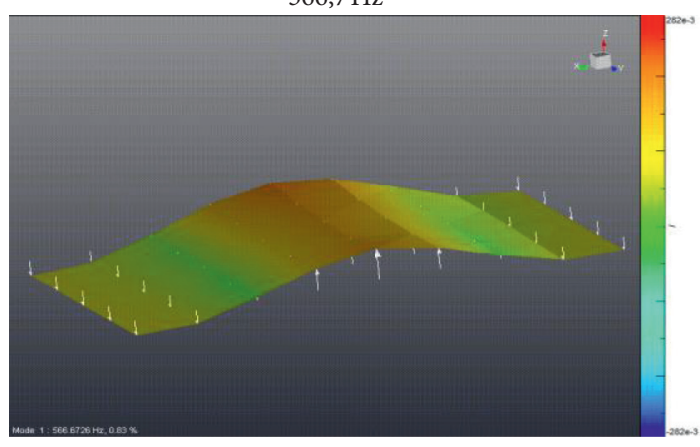

$991.7 \mathrm{~Hz}$

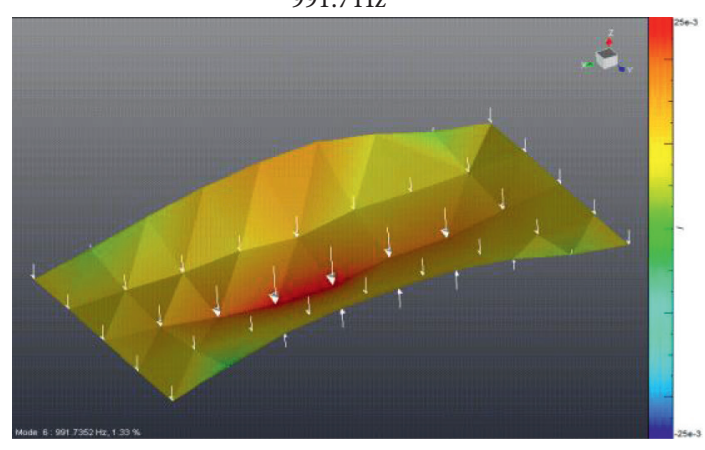

$1315.5 \mathrm{~Hz}$

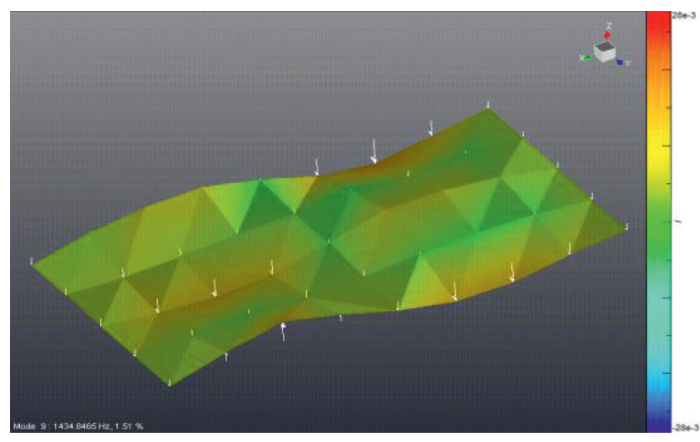

$332.95 \mathrm{~Hz}$

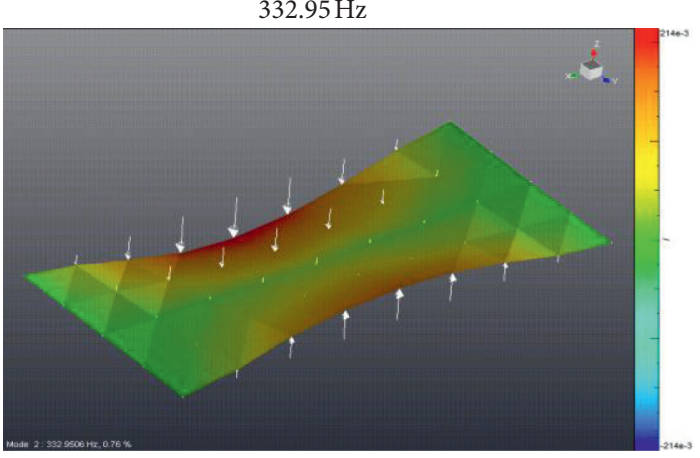

$759.1 \mathrm{~Hz}$

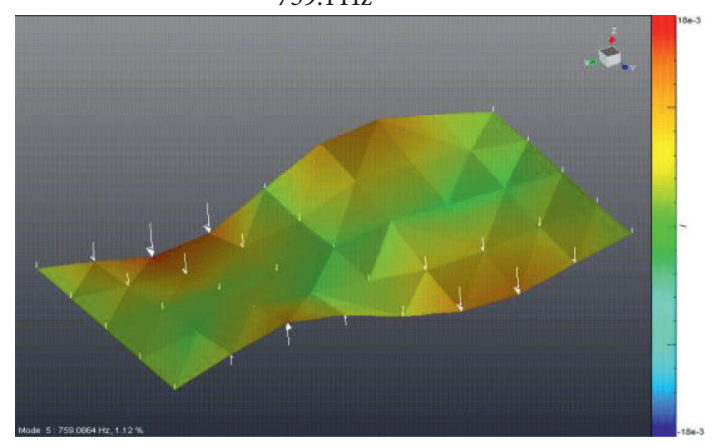

$1086.95 \mathrm{~Hz}$

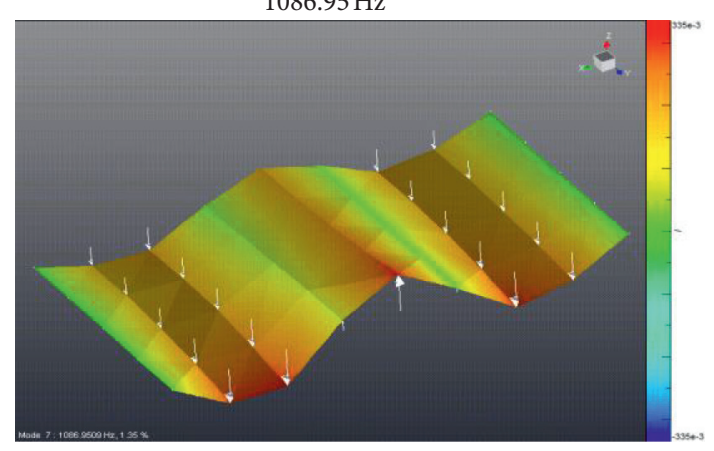

$1434.9 \mathrm{~Hz}$

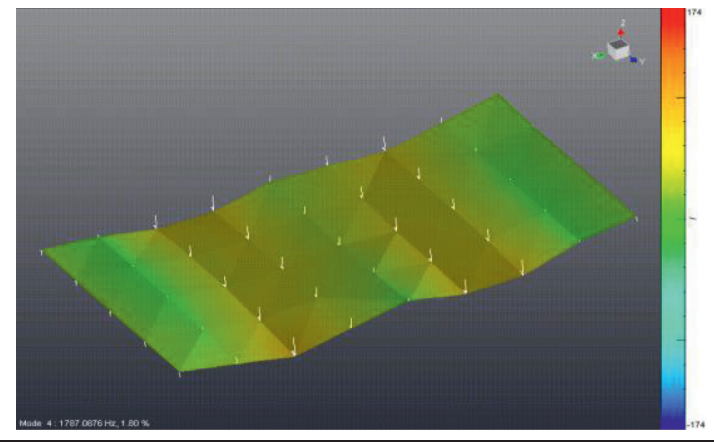


TABLE 6: Comparison of numerical and experimental frequencies (Case 1).

\begin{tabular}{lcc}
\hline FEM $(\mathrm{Hz})$ & Experimental $(\mathrm{Hz})$ & Difference $(\%)$ \\
\hline 203,58 & 214,00 & 4,87 \\
315,59 & 332,95 & 5,21 \\
560,42 & 566,67 & 1,10 \\
732,57 & 759,09 & 3,49 \\
998,60 & 991,74 & $-0,69$ \\
1101,56 & 1086,95 & $-1,34$ \\
1299,95 & 1315,54 & 1,19 \\
1428,81 & 1434,85 & 0,42 \\
\hline
\end{tabular}

TABLE 7: Geometrical properties and boundary conditions (Case 2).
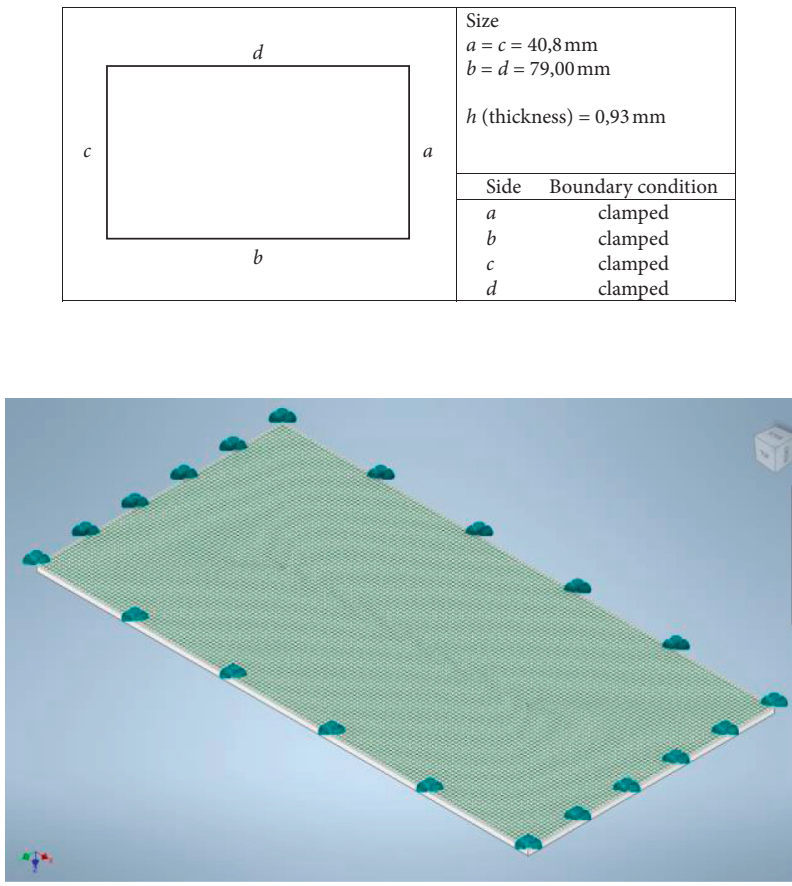

FIgURE 9: Numerical simulation: mesh and clamped edges.

From Table 6, it could be seen that the percental difference is less than $6 \%$ for the first cases, and it is decreasing for subsequent cases.

The analysis confirms a good agreement from finite element analysis and experimental modal analysis. In this test, the purpose is to verify that the identified material properties and the $3 \mathrm{D}$ printed boundary conditions are accurately made and that the specimen is realized with a pattern that allows to obtain global uniform structural properties of the specimen.

In the modelling process, it is well known that the most comfortable boundary conditions are the fixed joints because they allow to simplify the analysis reducing the complexity of the calculations; vice-versa in the experimental analysis, the free-free configurations result to be the easier to test because they reduce drastically the influence of the interaction of supporting frames or structural coupling with vibration table adapters.

These considerations are relevant from both the scientific point of view, when the experimental validation of a model is needed and when is required to model a real structure that is connected to a more complex system. This series of tests are used to validate reciprocally the FEM model, due to material uncertainties, and the experimental setup, due to the very critical experimental realization of clamping and hinges.

In particular, the $3 \mathrm{D}$ printing process provides a high versatility allowing to choose different materials and several patterns and parameters during the creation of the specimens; this, however, increases the complexity of the specimens introducing uncertainties that need to be taken into account during the modelling process.

Case 2. Rectangular plate with all edges clamped

In Table 7, the measured geometrical properties and the boundary conditions of the plate for the second case are listed.

4.3. FEM Simulation. For the finite element simulation, the Nastran solver has been used; in Figure 9, the mesh and the clamped edges are shown; results are given in Table 8. 
TABLE 8: FEM simulation: mode shapes and natural frequencies (Case 2).

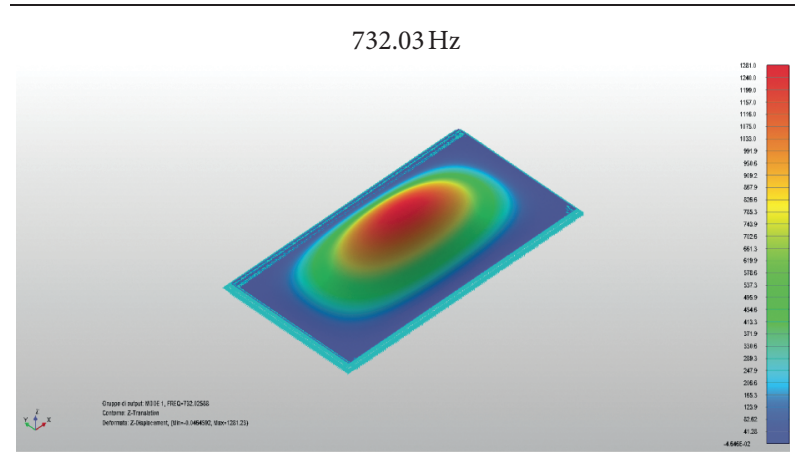

$1374.80 \mathrm{~Hz}$

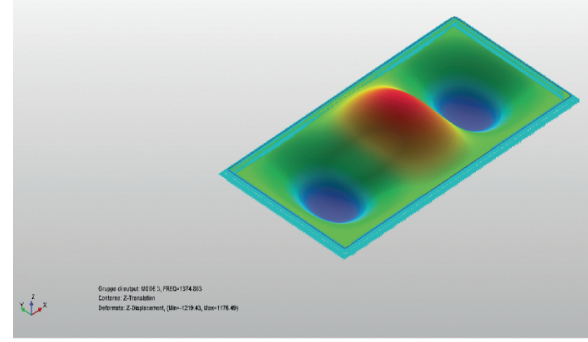

$1960.64 \mathrm{~Hz}$

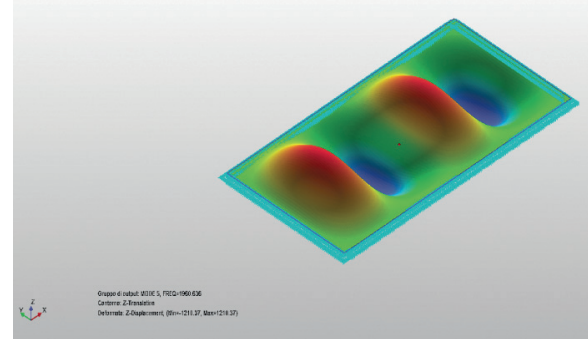

$2498.71 \mathrm{~Hz}$

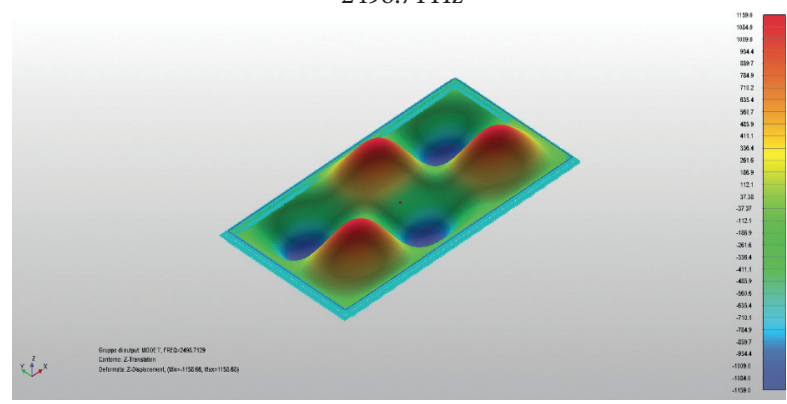

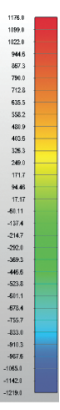

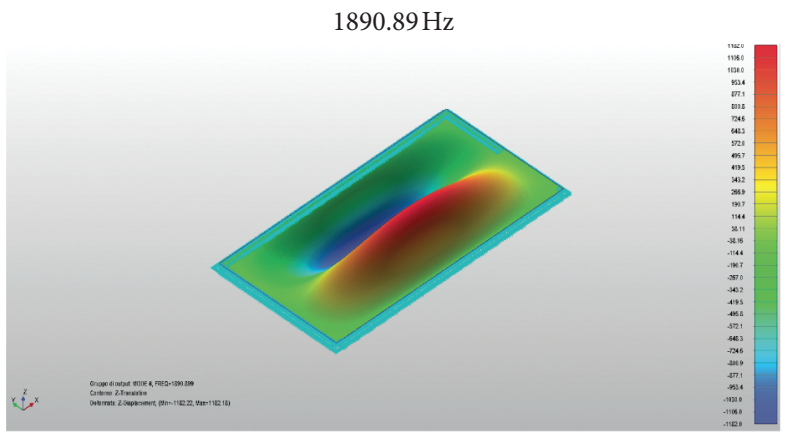

$2114.51 \mathrm{~Hz}$

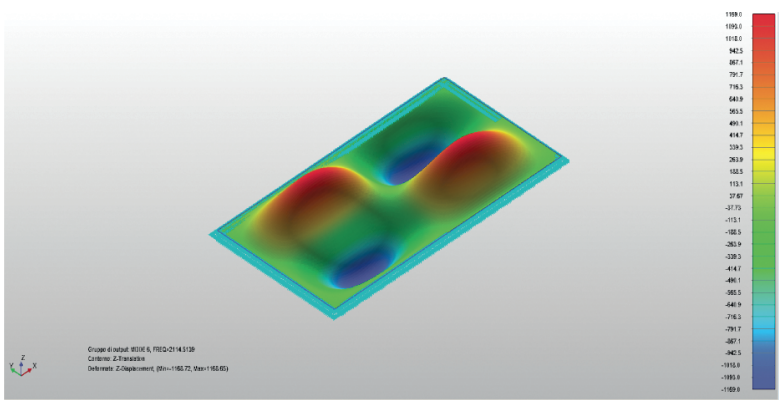

$2732.03 \mathrm{~Hz}$

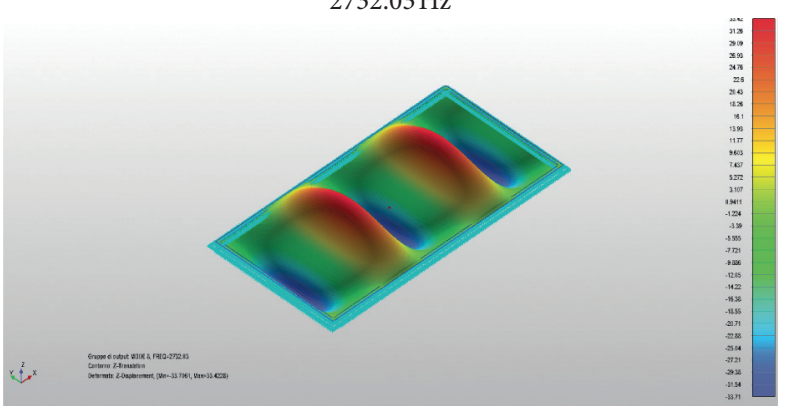

4.4. Experimental Modal Analysis. In Figure 10, the specimen mounted through the VTA (vibration table adapter) to the shaker is shown, and the laser spot during the measuring process is visible. In Figure 11, the experimental FRF (frequency response function) between base acceleration of the excitation and the measured velocity response of each point is presented. In Table 9, results are given.

In Table 10 , the $2^{\text {nd }}, 4^{\text {th }}$, and $7^{\text {th }}$ modes have a low correspondence probably due to a nonideal uniform clamping configuration along the specimen edges. 


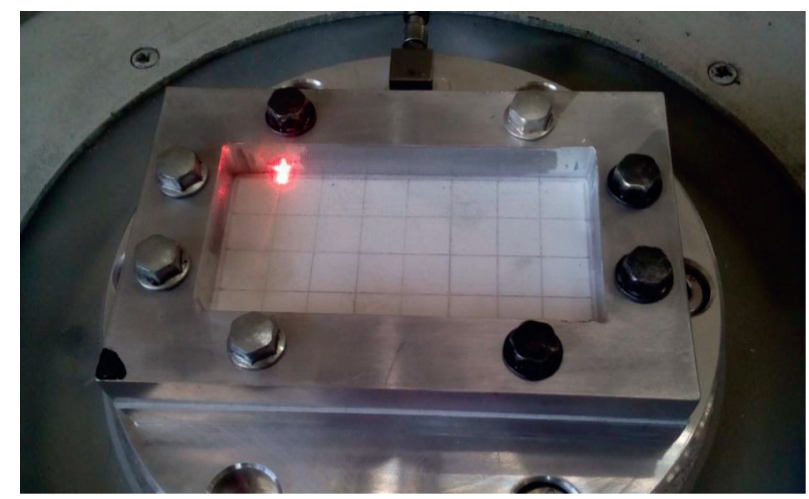

FIGURE 10: Specimen for experimental modal analysis (Case 2).

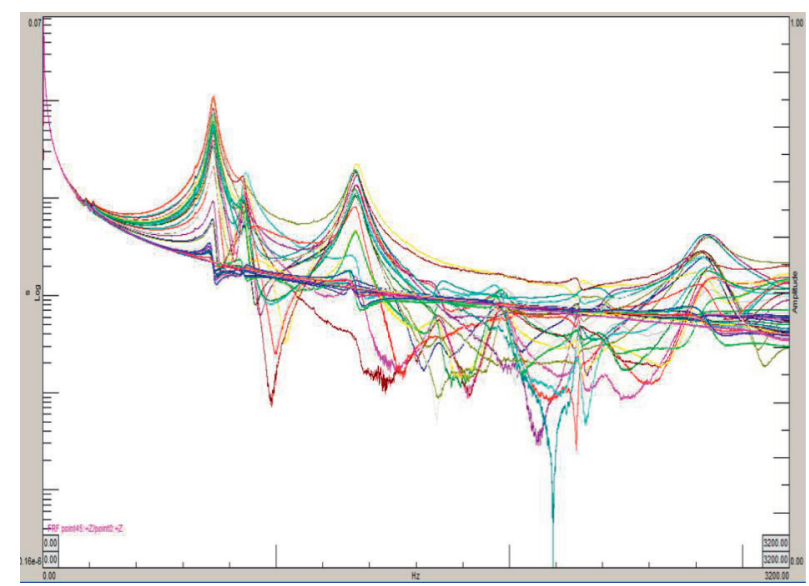

FIGURE 11: Experimental frequency response function base excitation vs velocity.

TABLE 9: Experimental modal analysis: mode shapes and natural frequencies (Case 2).

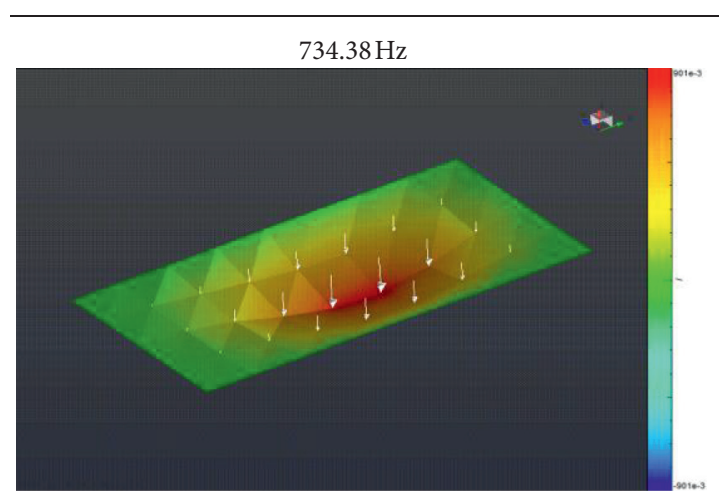

$869.61 \mathrm{~Hz}$

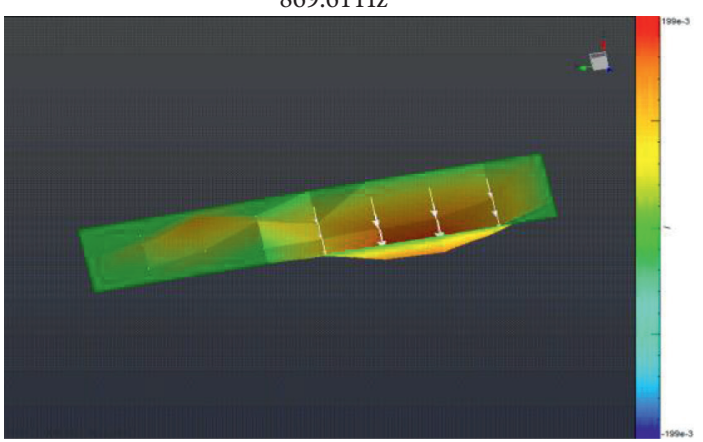

$1335.15 \mathrm{~Hz}$

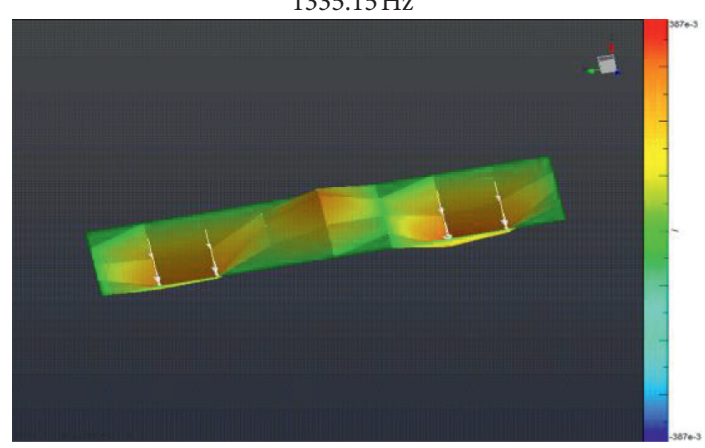

\section{$1692.04 \mathrm{~Hz}$}

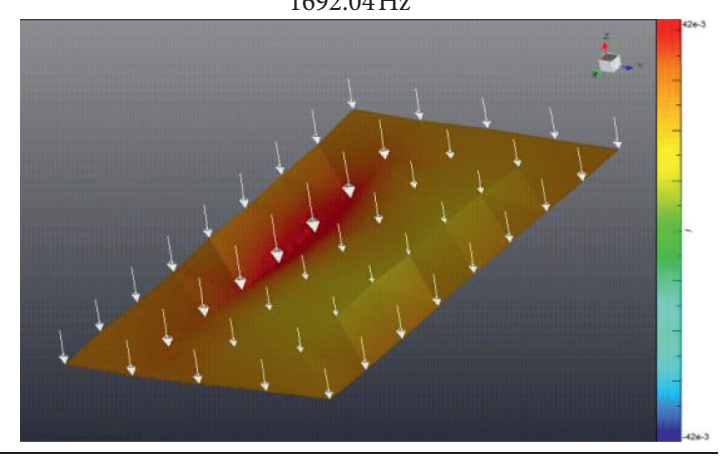


TABle 9: Continued.

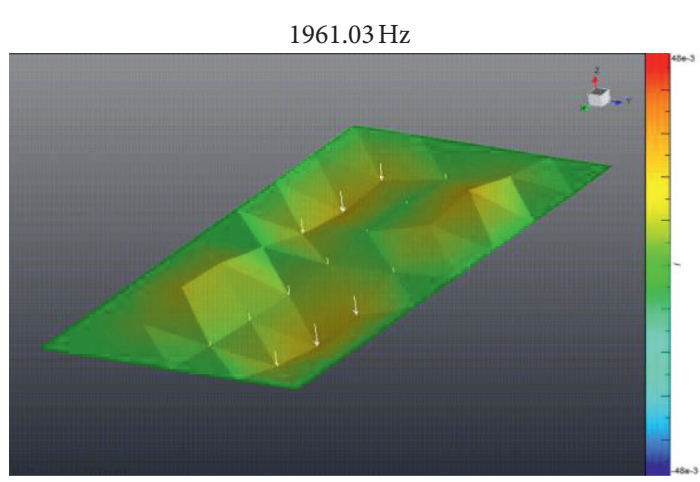

$2293.66 \mathrm{~Hz}$

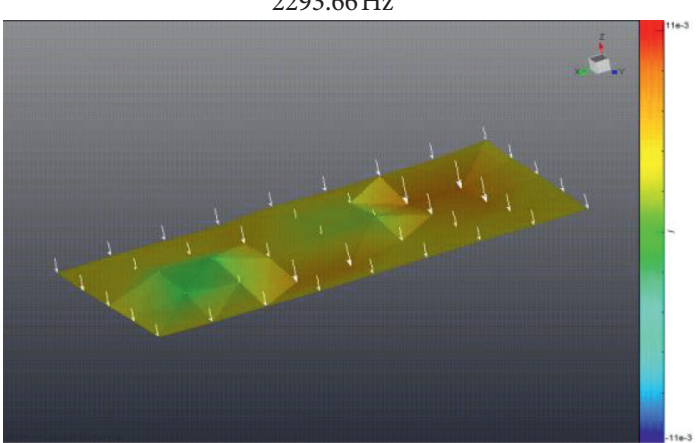

$2835.63 \mathrm{~Hz}$

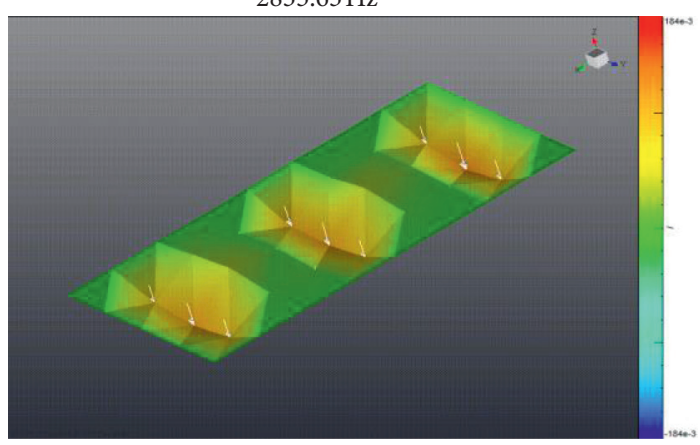

TABLE 10: Comparison of numerical and experimental frequencies (Case 2).

\begin{tabular}{lcc}
\hline FEM simulation $(\mathrm{Hz})$ & Experimental $(\mathrm{Hz})$ & Difference $(\%)$ \\
\hline 732,03 & 734,38 & 0,32 \\
963,65 & 869,61 & $-10,81$ \\
1374,80 & 1335,15 & $-2,97$ \\
1890,89 & 1692,04 & $-11,75$ \\
1960,64 & 1961,03 & 0,02 \\
2114,51 & 2293,66 & 7,81 \\
2498,71 & 2835,63 & 11,88 \\
\hline
\end{tabular}

TABLE 11: Geometrical properties and boundary conditions (Case 3).

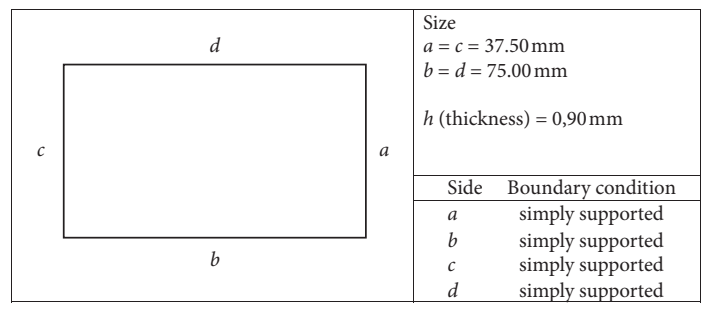

Case 3. Rectangular plate with all edges simply supported

In Table 11, the measured geometrical properties and the boundary conditions of the plate for the first case are listed.

4.5. FEM Simulation. For the finite element simulation, the Nastran solver has been used; in Figure 12, the mesh and the simply supported edges are shown; experimental results are given in Table 12 .
4.6. Experimental Modal Analysis. In Figure 13, the specimen realized with the $3 \mathrm{D}$ printer for the experimental modal analysis is shown, and a thinner boundary contour made to simulate the continuous hinge joint is clearly visible, while in Figure 14, the experimental FRF (frequency response function) between base acceleration of the excitation and the measured velocity response of each point is presented; it seems that the structure has a more dampened response due to the more smoothed curves 


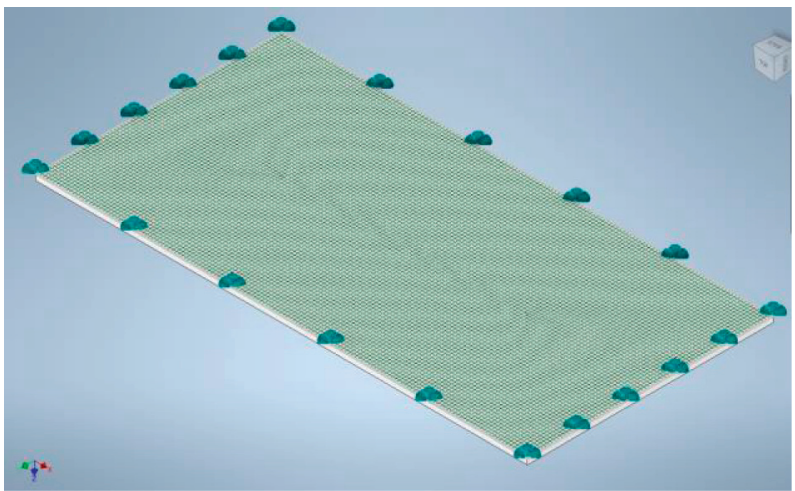

FIGURE 12: Numerical simulation: mesh and simply supported edges.

TABLE 12: FEM simulation: mode shapes and natural frequencies (Case 3).

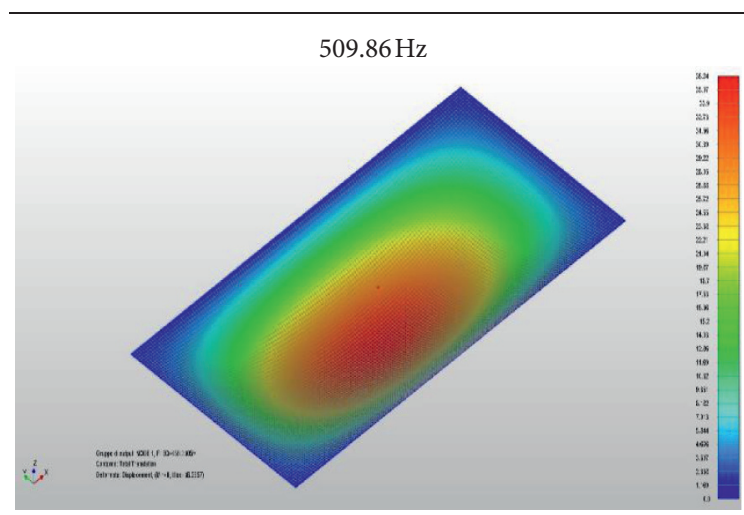

$1320.55 \mathrm{~Hz}$

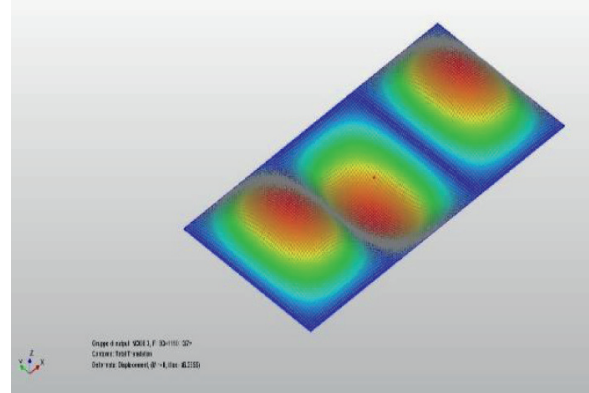

$2030.36 \mathrm{~Hz}$

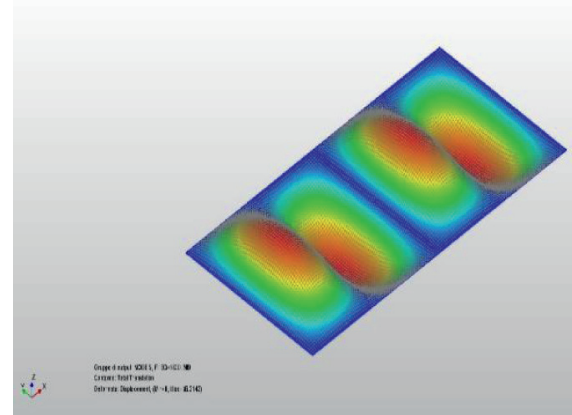

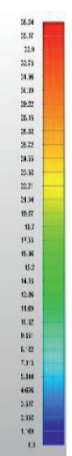

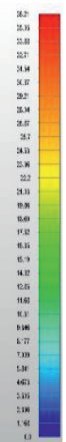

$813.04 \mathrm{~Hz}$

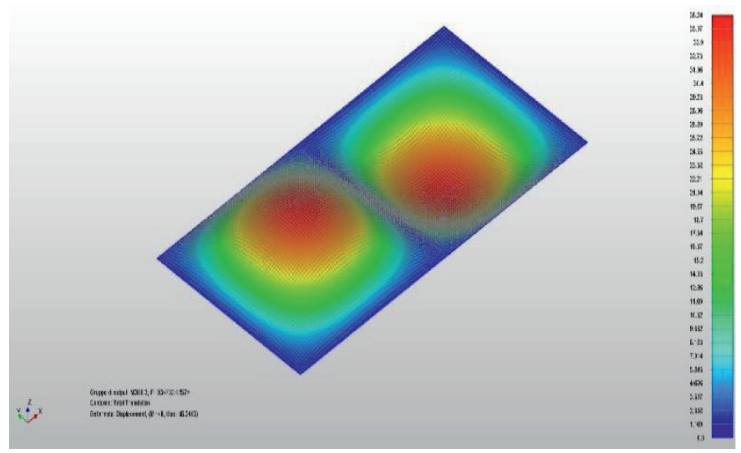

$1732.29 \mathrm{~Hz}$

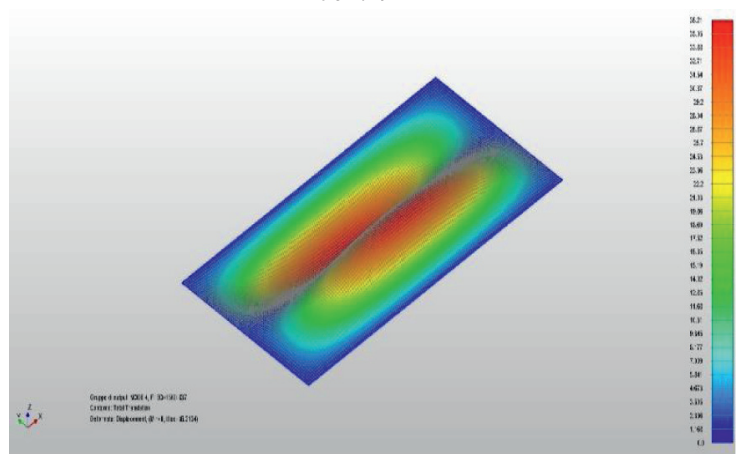

$2529.29 \mathrm{~Hz}$

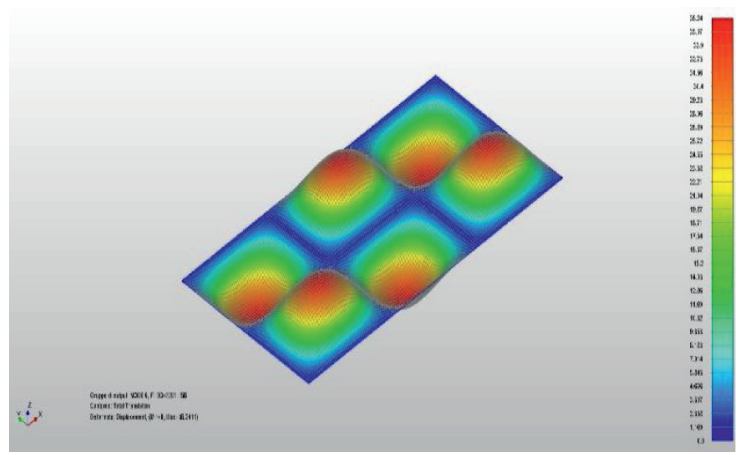


TABLE 12: Continued.
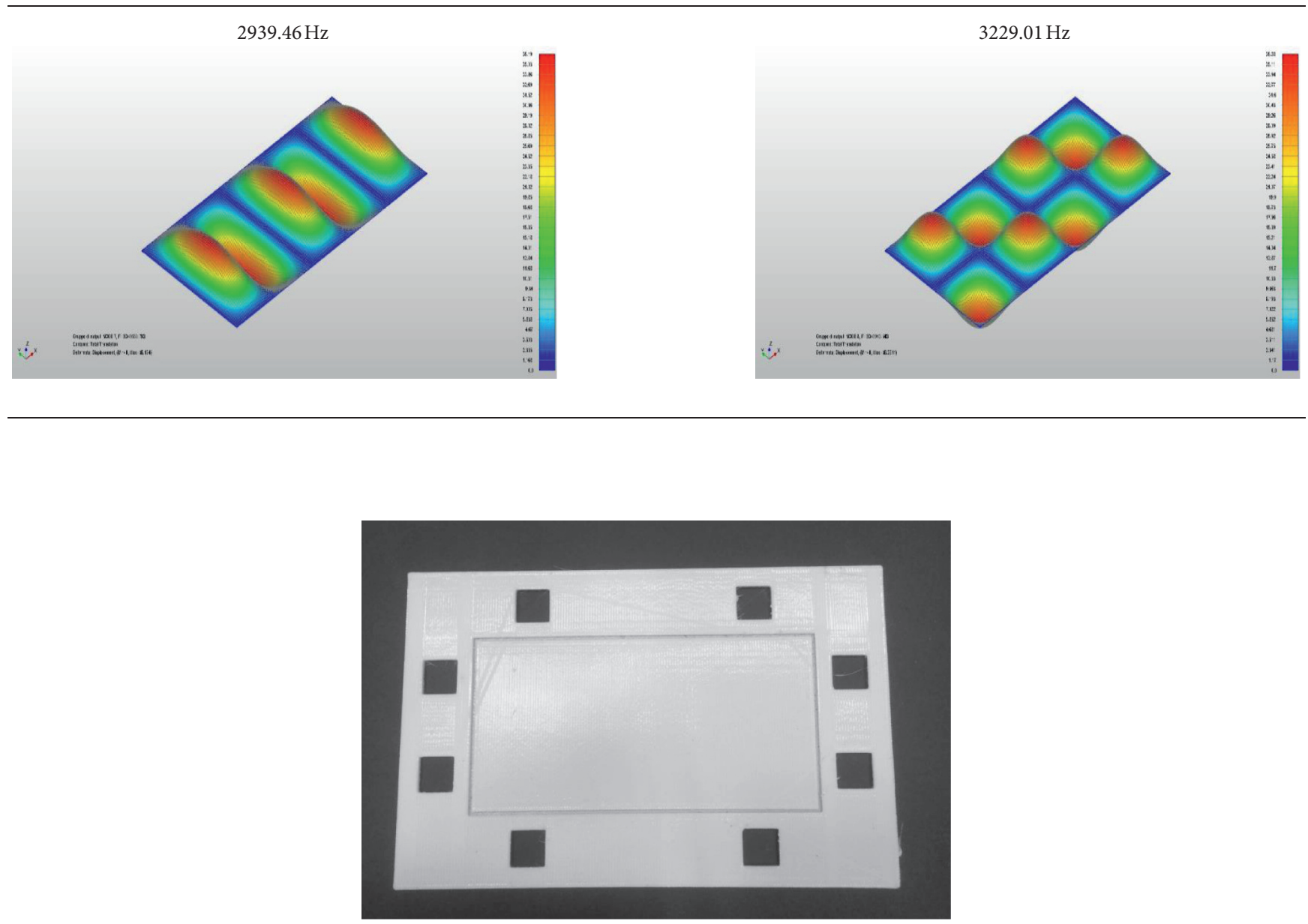

FIGURE 13: Specimen for experimental modal analysis (Case 3).

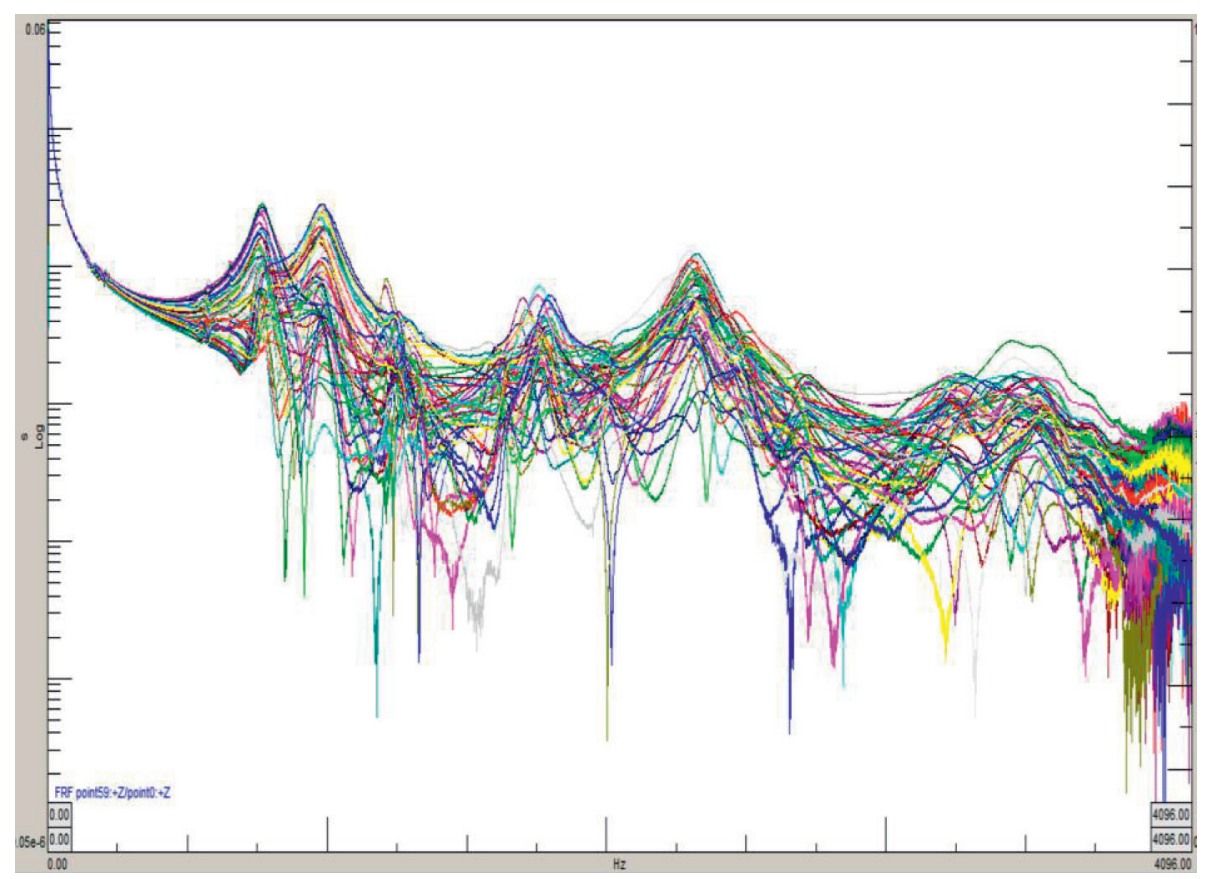

FIGURE 14: Experimental frequency response function base excitation vs velocity. 
TABLE 13: Experimental modal analysis: mode shapes and natural frequencies (Case 3).

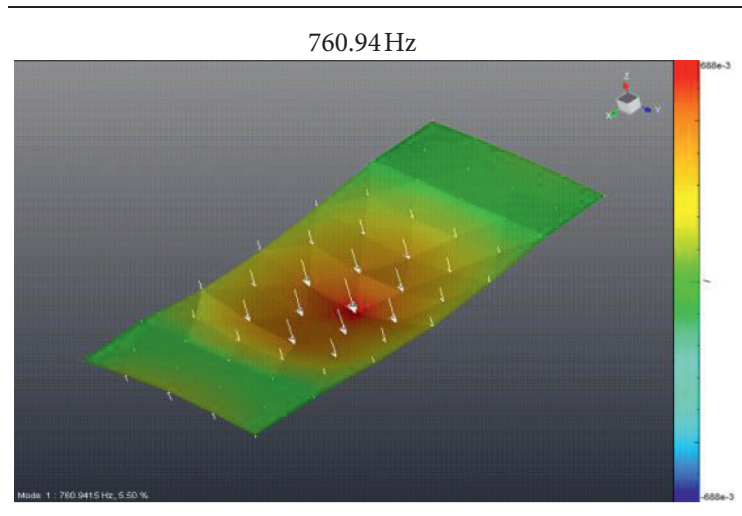

$1233.89 \mathrm{~Hz}$

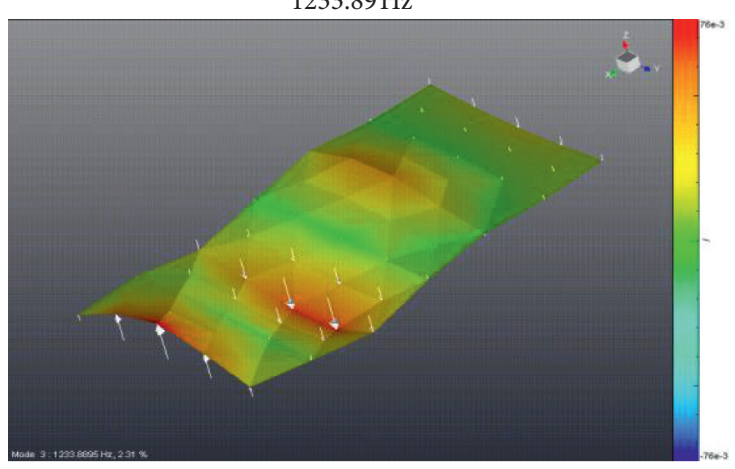

$1999.47 \mathrm{~Hz}$

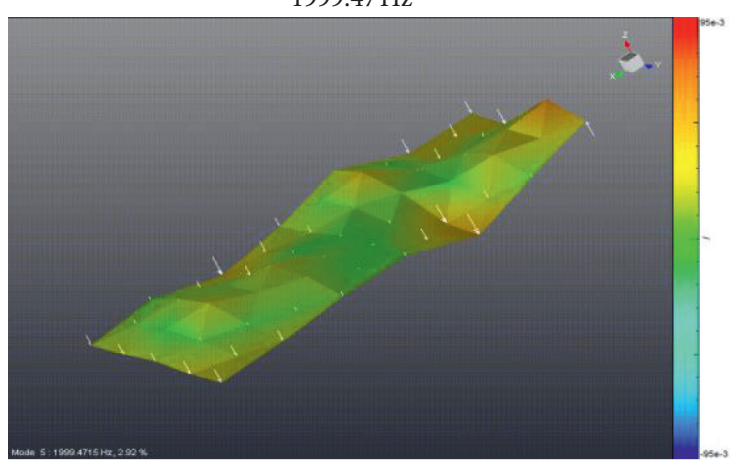

$3269.14 \mathrm{~Hz}$

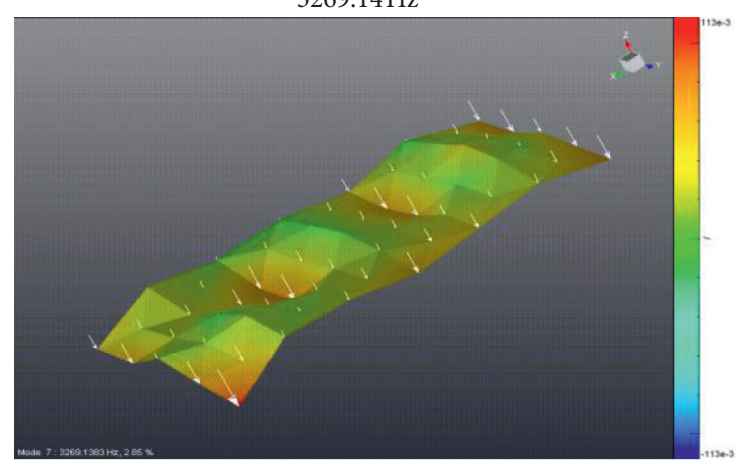

$980,59 \mathrm{~Hz}$

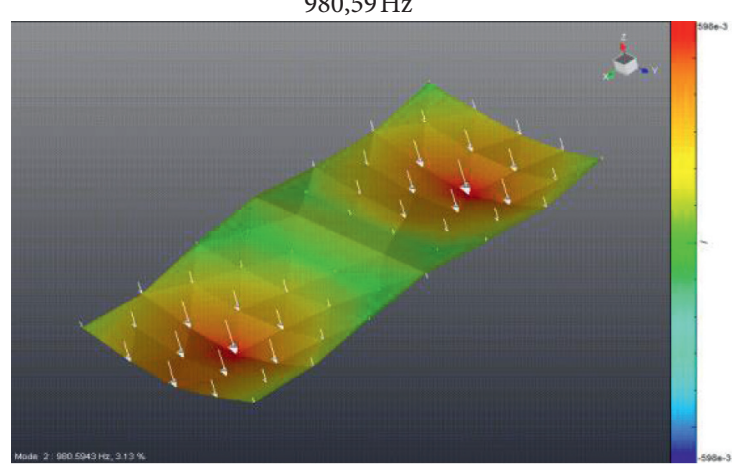

$1792.55 \mathrm{~Hz}$

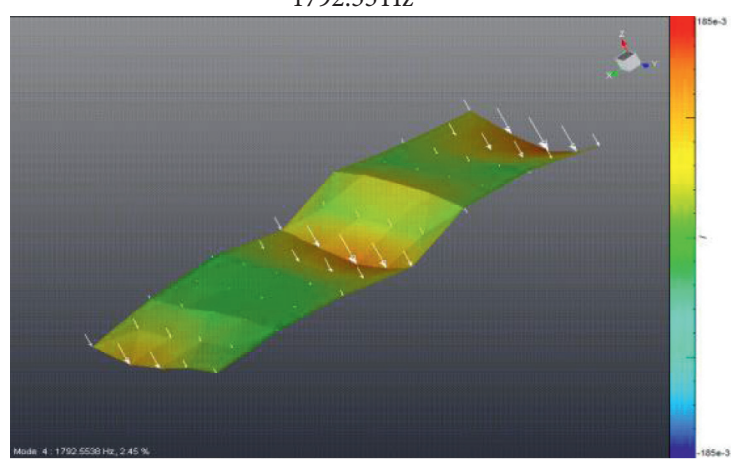

$2317.05 \mathrm{~Hz}$

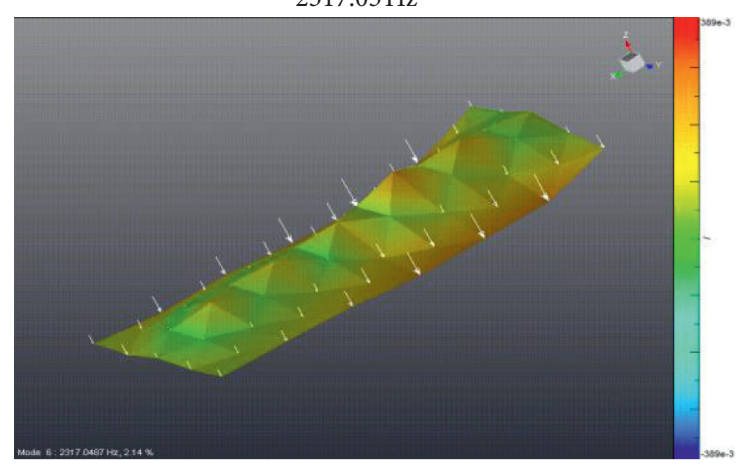

$3554.93 \mathrm{~Hz}$

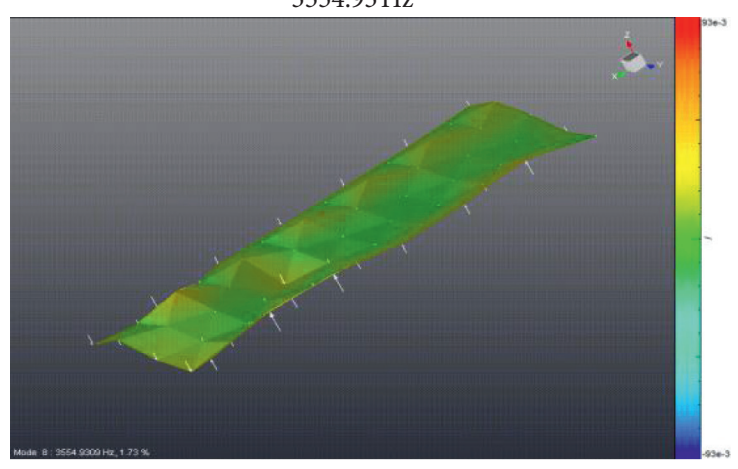


TABLE 14: Comparison of numerical and experimental frequencies (Case 3).

\begin{tabular}{lcc}
\hline FEM simulation $(\mathrm{Hz})$ & Experimental $(\mathrm{Hz})$ & Difference $(\%)$ \\
\hline 509,86 & 760,94 & 33,00 \\
813,04 & 980,59 & 17,09 \\
1320,55 & 1233,89 & $-7,02$ \\
1732,29 & 1792,55 & 3,36 \\
2030,36 & 1999,47 & $-1,54$ \\
2529,29 & 2317,05 & $-9,16$ \\
2939,46 & 3269,14 & 10,08 \\
3229,01 & 3554,93 & 9,17 \\
\hline
\end{tabular}

TABLE 15: Geometrical properties and boundary conditions (Case 4).
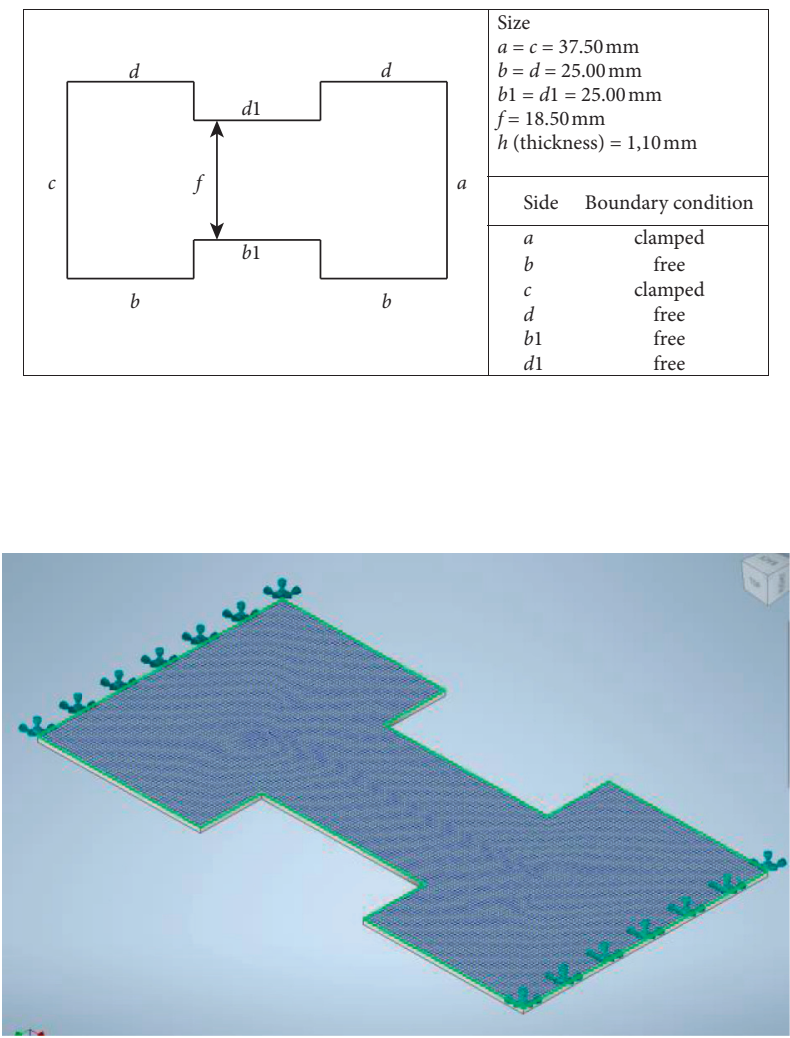

FIgURE 15: Numerical simulation: mesh and clamped edges.

TABLE 16: FEM simulation: mode shapes and natural frequencies (Case 4).

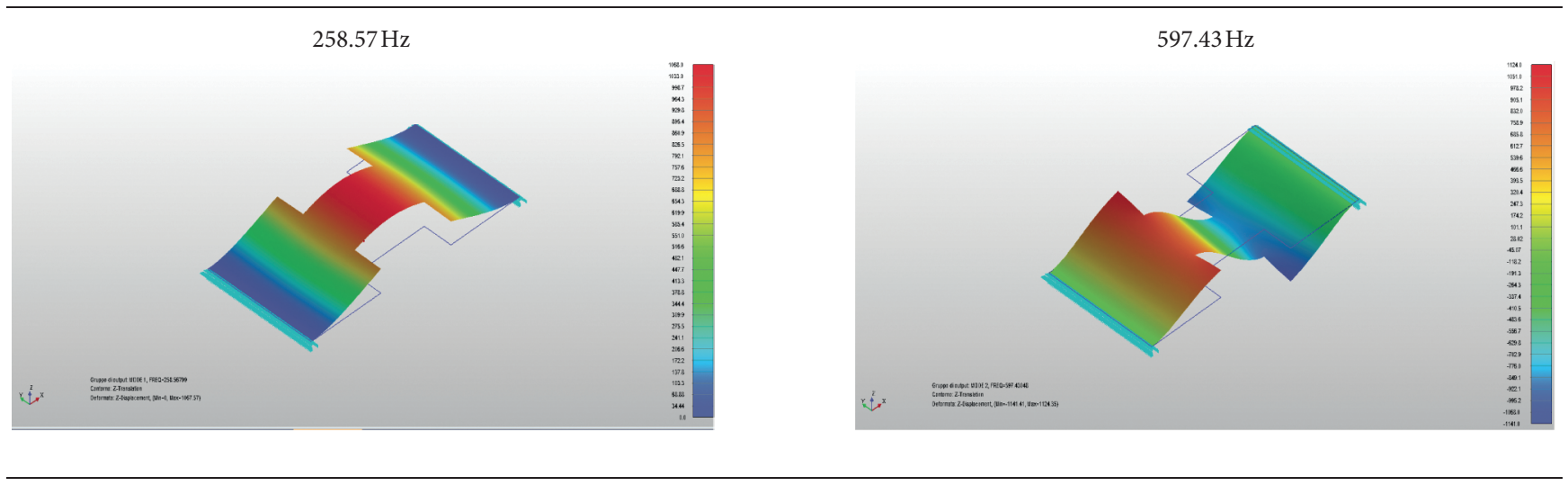


TABLE 16: Continued.
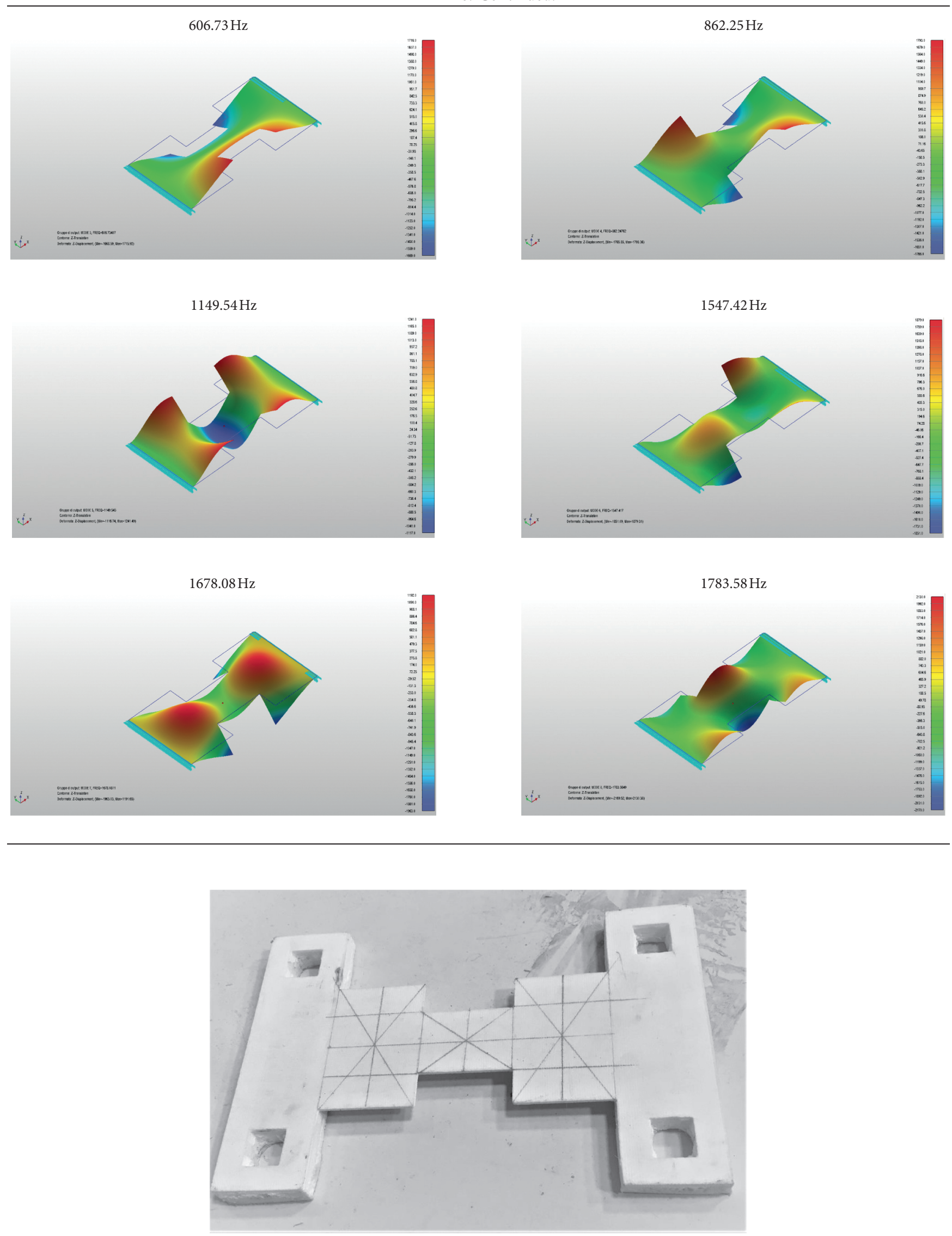

FIgURE 16: Specimen for experimental modal analysis (Case 4). 


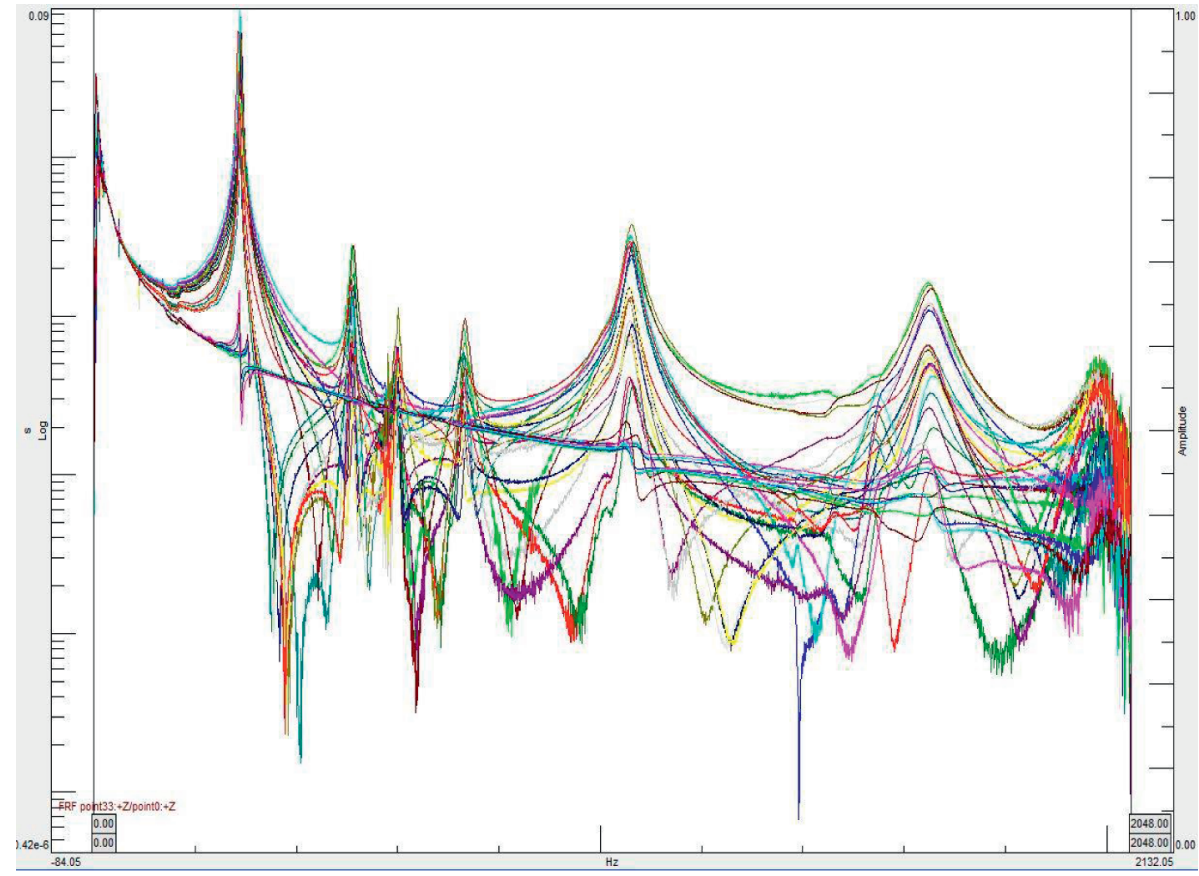

FIGURE 17: Experimental frequency response function base excitation vs velocity.

TABLE 17: Experimental modal analysis: mode shapes and natural frequencies (Case 4).

$287.82 \mathrm{~Hz}$

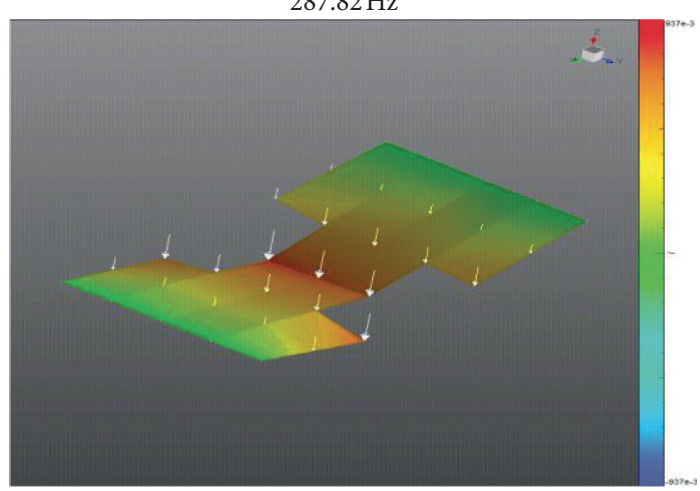

$598.59 \mathrm{~Hz}$

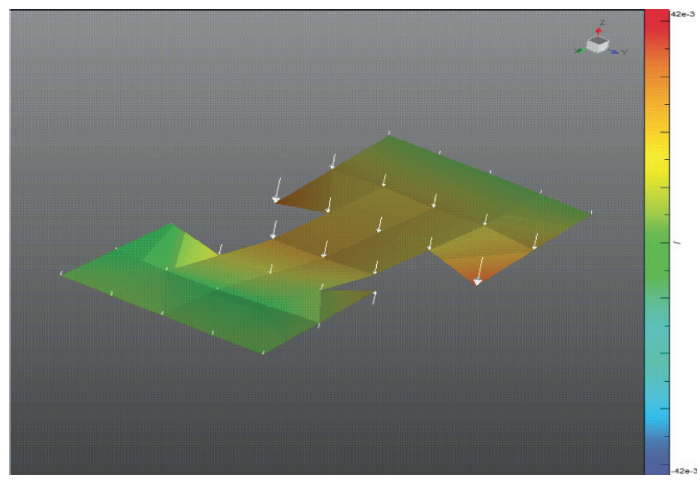

$509.47 \mathrm{~Hz}$

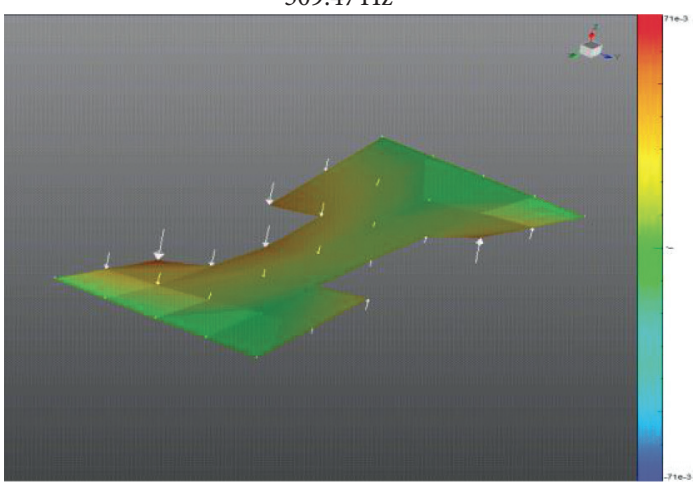

$730.24 \mathrm{~Hz}$

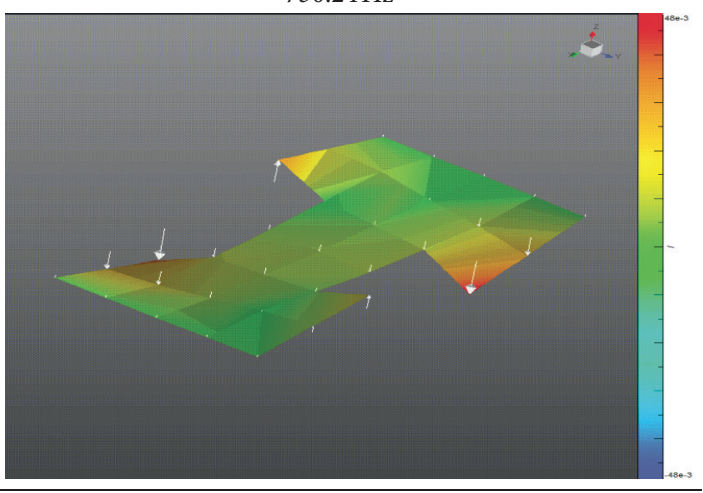


TABLE 17: Continued.

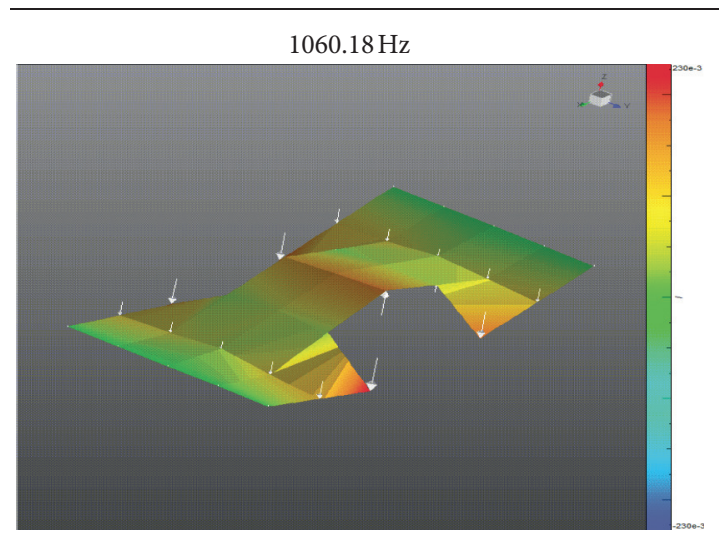

$1548.43 \mathrm{~Hz}$

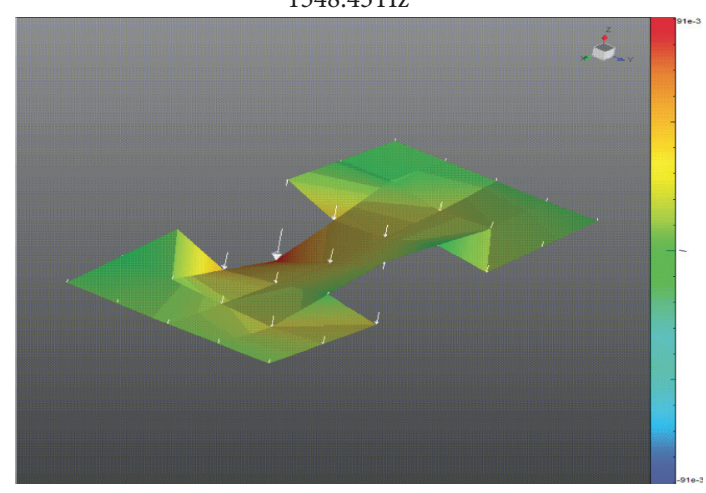

$1455.78 \mathrm{~Hz}$

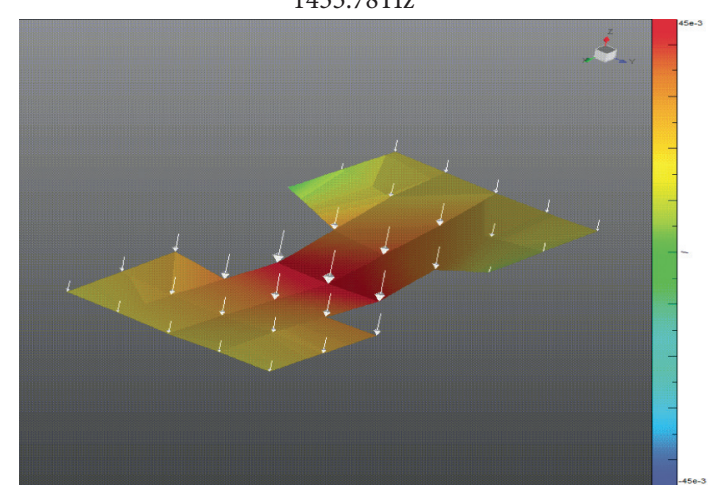

$1651.66 \mathrm{~Hz}$

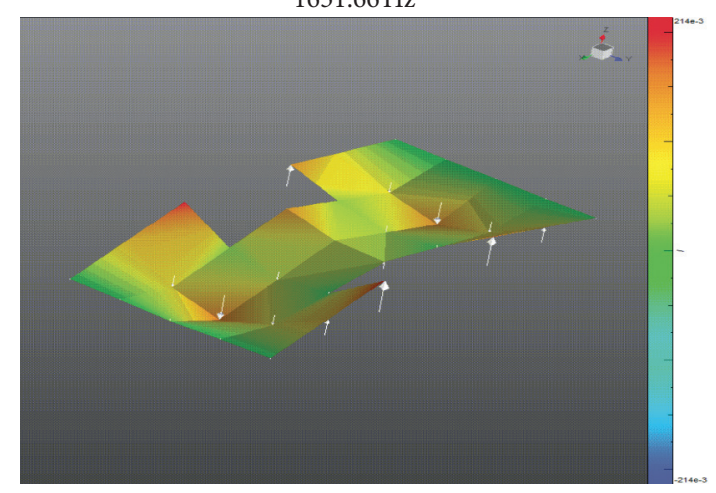

TABLE 18: Comparison of FEM and experimental frequencies (Case 4).

\begin{tabular}{lcc}
\hline FEM simulation $(\mathrm{Hz})$ & Experimental $(\mathrm{Hz})$ & Difference $(\%)$ \\
\hline 258,57 & 287,82 & 10,16 \\
597,43 & 509,47 & $-17,27$ \\
606,73 & 598,59 & $-1,36$ \\
862,25 & 730,24 & $-18,08$ \\
1149,54 & 1060,18 & $-8,43$ \\
1547,42 & 1455,78 & $-6,29$ \\
1678,08 & 1548,43 & $-8,37$ \\
1783,58 & 1651,66 & $-7,99$ \\
\hline
\end{tabular}

TABLE 19: $R$-functions method: mode shapes and natural frequencies (Case 4).

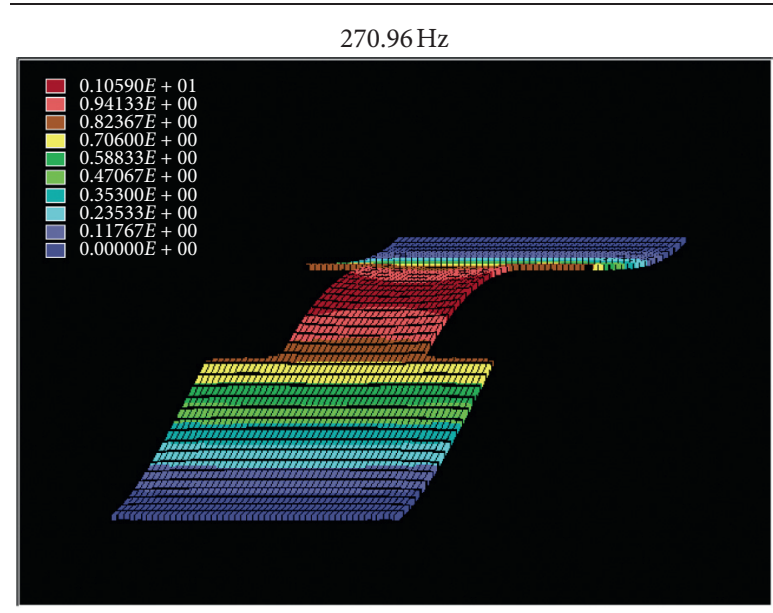

$555.64 \mathrm{~Hz}$

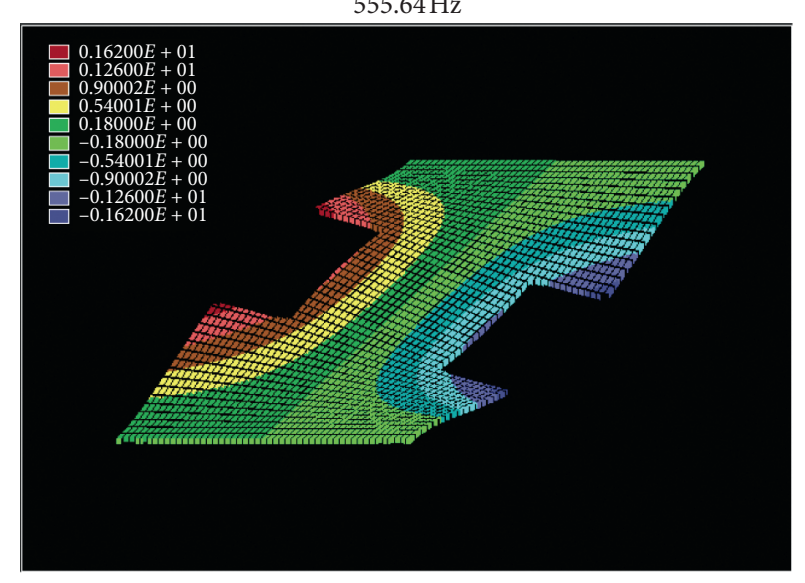


TABle 19: Continued.

$618.72 \mathrm{~Hz}$

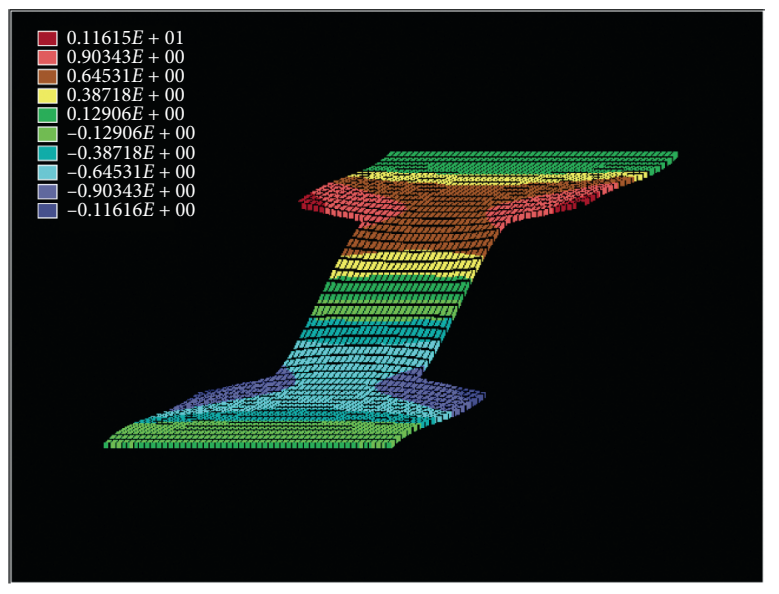

$1135.85 \mathrm{~Hz}$

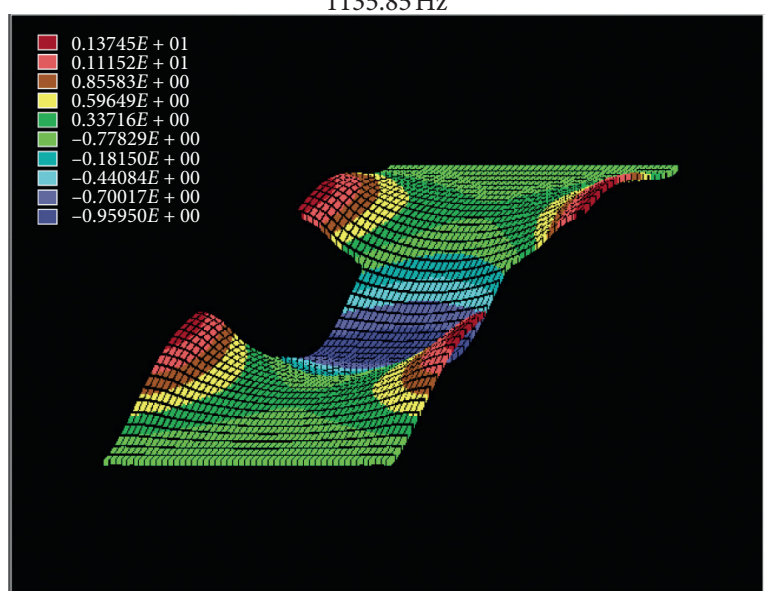

$1673.14 \mathrm{~Hz}$

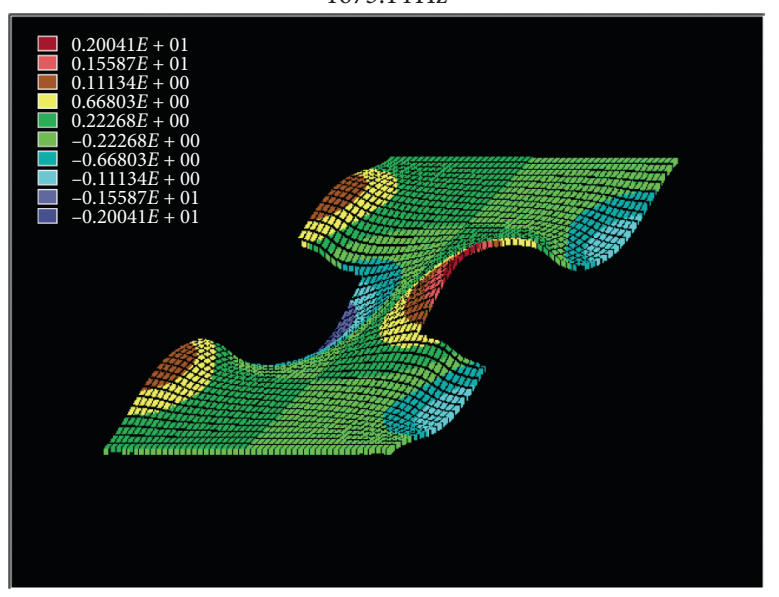

$805.71 \mathrm{~Hz}$

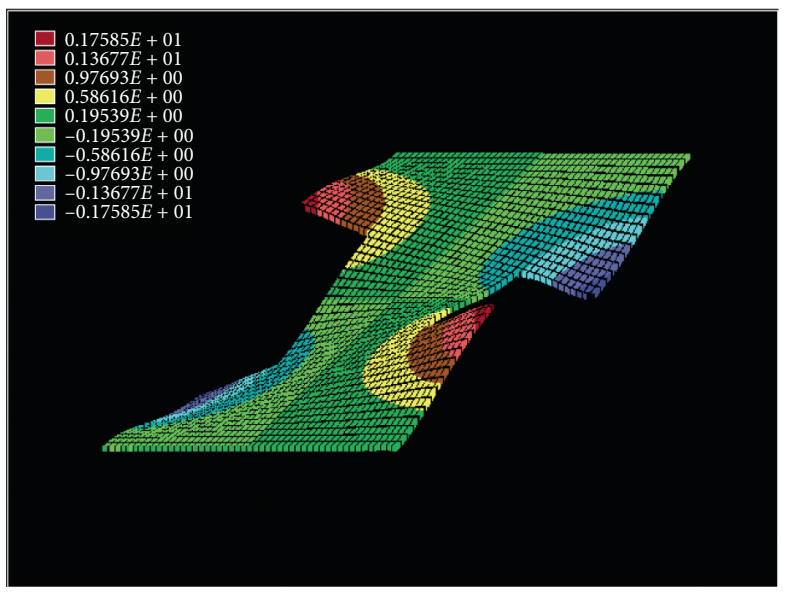

$1580.06 \mathrm{~Hz}$

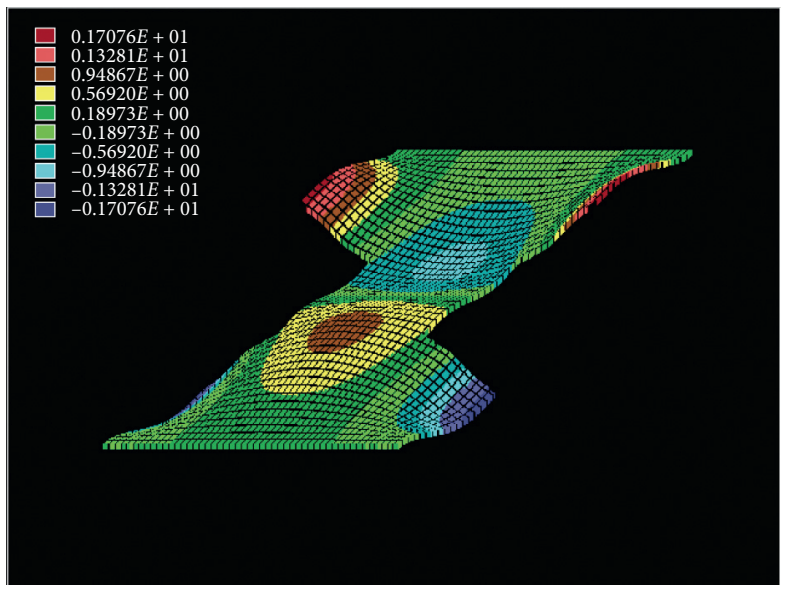

$1736.54 \mathrm{~Hz}$

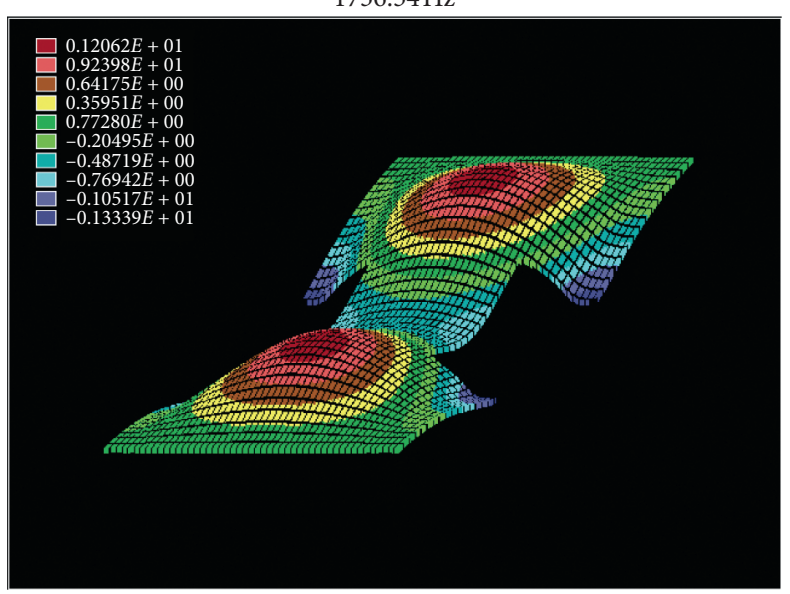

near the resonances. In Table 13, experimental results are given.

As it can be seen from the percentage differences, in Table 14, the effect of the boundary condition is present in the lowest and higher modes, the frequency of the first mode has a difference value more than $30 \%$ that exceeds an acceptable value, the second mode halved the percental difference with respect to the experimental analysis, and the 
TABLE 20: Comparison of experimental, FEM, and RFM frequencies (Case 4).

\begin{tabular}{lcccc}
\hline Experimental $(\mathrm{Hz})$ & FEM simulation $(\mathrm{Hz})$ & Difference $(\%)($ exp-FEM) & RFM $(\mathrm{Hz})$ & Difference $(\%)($ exp-RFM) \\
\hline 287,82 & 258,57 & 10,16 & 270.96 & $5.86 \%$ \\
509,47 & 597,43 & $-17,27$ & 555.64 & $-9.06 \%$ \\
598,59 & 606,73 & $-1,36$ & 618.72 & $-3.36 \%$ \\
730,24 & 862,25 & $-18,08$ & 805.71 & $-10.33 \%$ \\
1060,18 & 1149,54 & $-8,43$ & 1135.85 & $-7.14 \%$ \\
1455,78 & 1547,42 & $-6,29$ & 1580.06 & $-8.54 \%$ \\
1548,43 & 1678,08 & $-8,37$ & 1673.14 & $-8.05 \%$ \\
1651,66 & 1783,58 & $-7,99$ & 1736.54 & $-5.14 \%$ \\
\hline
\end{tabular}

other modes are not uniform, and we can assume that this is due to the fact that the constraint has not been modelled exactly or vice-versa that the creation of the specimen hinge joint is too much stiff and interacts with the frame structure.

Case 4. Rectangular plate with symmetric rectangular cuts In Table 15, the measured geometrical properties and the boundary conditions of the plate for the first case are listed.

4.7. FEM Simulation. For the finite element simulation, the Nastran solver has been used; in Figure 15, the mesh and the opposite clamped edges are shown; experimental results are given in Table 16.

4.8. Experimental Modal Analysis. In Figure 16, the specimen realized with the $3 \mathrm{D}$ printer for the experimental modal analysis is shown, while in Figure 17, the experimental FRF (frequency response function) between base acceleration of the excitation and the measured velocity response of each point is presented. In Table 17, experimental results are given.

In Table 18, a comparison between the finite element method and the experimental modal analysis is given.

4.9. R-Functions Simulation. In Table 19, the results of the simulation using the $R$-functions method are given.

The proposed case takes an advantage of the previous analysis, used for the mutual validation of the fixed-fixed configuration, for testing a plate with a complex form and two clamped sides. In Table 20, the comparison of the experimental modal analysis with respect to the finite element method and the $R$-functions method is presented. The $R$ functions method shows better correspondence, an average difference of $7.2 \%$, concerning the finite element modelling that presents an average difference of $9.7 \%$. Moreover, the first and second modes are better modelled, as well as the $4^{\text {th }}$ mode. These discrepancies could be addressed to the difficulty in modelling and realizing an ideal boundary condition.

\section{Conclusion}

In this work, a comparison of three methods to analyze the dynamic behavior of 3D-printed specimens with complex plate shapes and different boundary conditions is fulfilled. The used method and the experimental procedure and facilities are accurately reported, and the material properties of the plates are described. The 2 fixed-sided configuration presents a more solid agreement both in the rectangular plate and in the plate with rectangular cuts, and the $R$-functions method seems to be more similar with respect to the experimental test in comparison with the finite element analysis. The simply supported configuration shows difficulties in the continuous hinge joint realization of the specimen to be correctly modelled.

The experimental analysis reflects the complexity to rightly make a fixed or hinge joint in a real test case, and the finite element method reveals these challenges to the modelling point of view. Since the $R$-functions method represents the solution in an analytical form, this distinguishes it favorably from the finite element method when solving nonlinear problems.

\section{Data Availability}

The experimental data used to support the findings of this study are available from the corresponding author upon request.

\section{Conflicts of Interest}

The authors declare that there are no conflicts of interest regarding the publication of this paper.

\section{Acknowledgments}

The authors would like to thank InterMech MO.RE. Center. This research received the support of the project DiaPro4.0: "Cost-effective" Multisensor Diagnostic-Prognostic Integrated System in Mechanical Drives for Industry 4.0 (PG/ 2018/632156)-CUP F44I18000030009.

\section{References}

[1] M. Amabili, Nonlinear Vibrations and Stability of Shells and Plates, Cambridge University Press, Cambridge, UK, 2008.

[2] A. Zippo, M. Barbieri, G. Iarriccio, and F. Pellicano, "Nonlinear vibrations of circular cylindrical shells with thermal effects: an experimental study," Nonlinear Dynamics, vol. 99, no. 1, p. 373, 2020.

[3] G. Iarriccio, A. Zippo, F. Pellicano, and M. Barbieri, "Resonances and nonlinear vibrations of circular cylindrical shells, effects of thermal gradients," Proceedings of the Institution of 
Mechanical Engineers, Part C: Journal of Mechanical Engineering Science, 2020.

[4] T. J. Anderson and A. H. Nayfeh, "Natural frequencies and mode shapes of laminated composite plates: experiments and FEA," Journal of Vibration and Control, vol. 2, no. 4, pp. 381-414, 1996.

[5] D. Shi, X. Shi, W. L. Li, Q. Wang, and J. Han, "Vibration analysis of annular sector plates under different boundary conditions," Shock and Vibration, vol. 2014, p. 1, Article ID 517946, 2014.

[6] E. F. Joubaneh, O. R. Barry, and H. E. Tanbour, "Analytical and experimental vibration of sandwich beams having various boundary conditions," Shock and Vibration, vol. 2018, p. 1, Article ID 3682370, 2018.

[7] F. Tornabene and E. Viola, "Vibration analysis of spherical structures elements using the GDQ method," Computers and Mathematics with Applications, vol. 53, pp. 1538-1560, 2007.

[8] S. Pradyumna and J. N. Bandyopadhyay, "Free vibration analysis of functionally graded curved panels using a higherorder finite element formulation," Journal of Sound and Vibration, vol. 318, no. 1-2, pp. 176-192, 2008.

[9] A. M. A. Neves, A. J. M. Ferreira, E. Carrera, M. Cinefra, C. M. C. Roque, and R. M. N. Jorge, "Free vibration analysis of functionally graded shells by a higher-order shear deformation theory and radial basis functions collocation accounting for through the thickness deformations," European Journal of Mechanics-A/Solids, vol. 37, pp. 24-34, 2013.

[10] J. Awrejcewicz, L. Kurpa, and T. Shmatko, "Investigating geometrically nonlinear vibrations of laminated shallow shells with layers of variable thickness via the R-functions theory," Composite Structures, vol. 125, pp. 575-585, 2015.

[11] G. Pilgun and M. Amabili, "Non-linear vibrations of shallow circular cylindrical panels with complex geometry. Meshless discretization with the R-functions method," International Journal of Non-linear Mechanics, vol. 47, no. 3, pp. 137-152, 2012.

[12] J. Awrejcewicz, L. Kurpa, and T. Shmatko, "Linear and nonlinear free vibration analysis of laminated functionally graded shallow shells with complex plan form and different boundary conditions," International Journal of Non-linear Mechanics, vol. 107, p. 161, 2018.

[13] L. Kurpa, G. Pilgun, and M. Amabili, "Nonlinear vibrations of shallow shells with complex boundary: R-functions method and experiments," Journal of Sound and Vibration, vol. 306, no. 3-5, pp. 580-600, 2007.

[14] V. L. Rvachev, The R-Functions Theory and its Some Application, Naukova Dumka, Kiev, Ukraine, in Russian, 1982.

[15] L. V. Kurpa, R-functions Method for Solving Linear Problems of Bending and Vibrations of Shallow Shells, Kharkiv NTU Press, Kharkiv, Ukraine, in Russian, 2009. 